\title{
The Influence of Rear Turn Signal Characteristics on Crash Risk
}


This publication is distributed by the U.S. Department of Transportation, National Highway Traffic Safety Administration, in the interest of information exchange. The opinions, findings, and conclusions expressed in this publication are those of the author(s) and not necessarily those of the Department of Transportation or the National Highway Traffic Safety Administration. The United States Government assumes no liability for its content or use thereof. If trade or manufacturers' names or products are mentioned, it is because they are considered essential to the object of the publication and should not be construed as an endorsement. The United States Government does not endorse products or manufacturers.

Note: Agency staff will be performing additional analysis on the safety effectiveness of amber/red turn signals. Once that work is complete, the agency will conclude whether any action may be warranted. 
Technical Report Documentation Page

\begin{tabular}{|c|c|c|}
\hline $\begin{array}{l}\text { 1. Report No. } \\
\text { DOT HS } 811037\end{array}$ & 2. Government Accession No. & 3. Recipient's Catalog No. \\
\hline \multirow{2}{*}{\multicolumn{2}{|c|}{$\begin{array}{l}\text { 4. Title and Subtitle } \\
\text { The Influence of Rear Turn Signal Characteristics on Crash } \\
\text { Risk }\end{array}$}} & $\begin{array}{l}\text { 5. Report Date } \\
\text { September } 2008\end{array}$ \\
\hline & & \begin{tabular}{|l} 
6. Performing Organization Code \\
\end{tabular} \\
\hline \multicolumn{2}{|c|}{$\begin{array}{l}\text { 7. Author(s) } \\
\text { John M. Sullivan and Michael J. Flannagan }\end{array}$} & 8. Performing Organization Report No. \\
\hline \multirow{2}{*}{\multicolumn{2}{|c|}{$\begin{array}{l}\text { 9. Performing Organization Name and Address } \\
\text { The University of Michigan } \\
\text { Transportation Research Institute } \\
\text { 2901 Baxter Road } \\
\text { Ann Arbor, MI 48109-2150 U.S.A }\end{array}$}} & 10. Work Unit no. (TRAIS) \\
\hline & & $\begin{array}{l}\text { 11. Contracts or Grant No. } \\
\text { DTNH22-05-D-01019 }\end{array}$ \\
\hline \multirow{2}{*}{\multicolumn{2}{|c|}{$\begin{array}{l}\text { 12. Sponsoring Agency Name and Address } \\
\text { National Highway Transportation Safety Administration } \\
1200 \text { New Jersey Avenue SE. } \\
\text { Washington, DC } 20590\end{array}$}} & 13. Type of Report and Period Covered \\
\hline & & 14. Sponsoring Agency Code \\
\hline
\end{tabular}

The relationship between the relative risk of a rear-end collision involving a turn, merge, or lane change maneuver and the characteristics of the rear turn-signal configuration was examined using rear-end collision crash data pooled from seven States. To perform the analysis, a detailed database of rear signal characteristics was developed for the vehicles most frequently involved in crashes among five of the States. The signal lamp characteristics were combined with other factors contained in the crash record in a stepwise logistic regression that modeled the odds of a rear-end collision while performing a turnsignal-related maneuver as a function of all of these factors. Two contrast groups were used as the denominator of the odds ratio in separate analyses. The first contrast group was comprised of the striking vehicles involved in turn-signal-related rear-end collisions. The second contrast group was comprised of rear-struck vehicles not engaged in turn-signal relevant maneuvers.

The first analysis suggests that there is an association between amber turn signals and a reduction of between 3 and 28 percent in the odds of being the struck (versus striking) vehicle in a turn-signalrelevant maneuver. The second analysis found no association between turn signal color and the odds of being struck in a turn-signal-relevant maneuver. The differences in the two analyses are discussed in terms of how well the respective contrast groups are insulated from potential effects of turn signal configurations.

Additional analyses substituted vehicle series name with body style as a predictor in the model, and examined turn signal characteristics in vehicles that have been produced with both amber and red turn signals at different times.

Although the analysis suggests that there may be a safety benefit associated with amber turn signals, it is unclear that turn signal color itself is completely responsible for the benefit. Further investigation of factors confounded with lamp color seems warranted before drawing a strong conclusion that turn signal color, by itself, is responsible for the observed differences.

\begin{tabular}{l|l|l} 
17. Key Words & 18. Distribution Statement
\end{tabular}

Turn signals, crash risk, amber turn signals, $\quad$ Unlimited rear-end collisions 


\section{Contents}

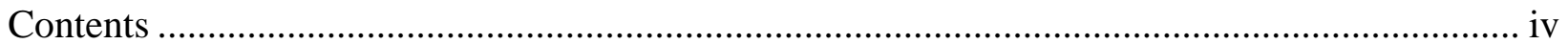

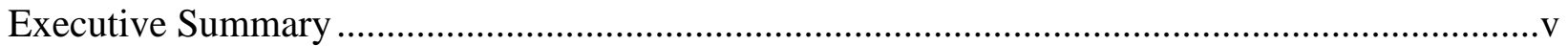



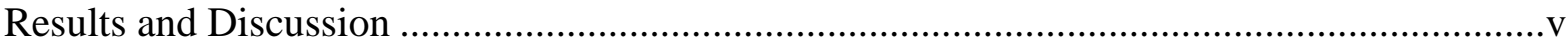

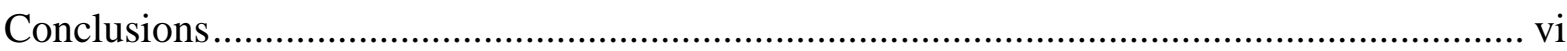

Part I: The Association of Turn Signal Characteristics With Rear-End Collisions .......................1

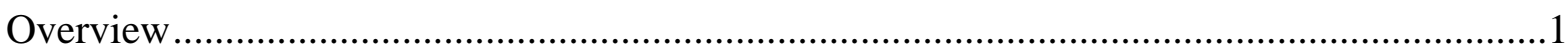

Signal characteristics related to crash risk ......................................................................

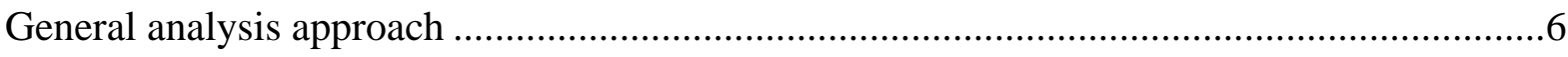

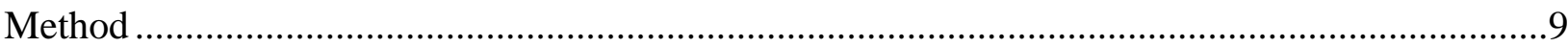

Vehicle Selection and Rear Signal Database Development ................................................9

Crash Scenario Selection and Data Processing...........................................................15

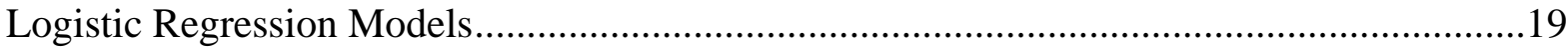

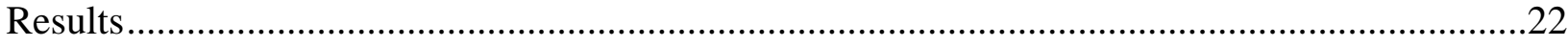

Analysis 1: Log Odds of Struck/Striking Role ............................................................22

Analysis 2: Log Odds of Relevant/Non-Relevant Collisions ............................................27

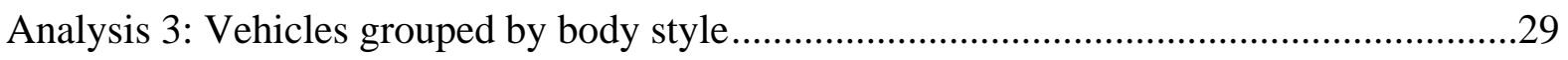

Analysis 4: Turn-signal color changes within models ......................................................33

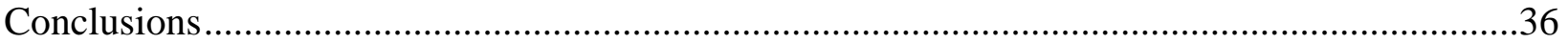

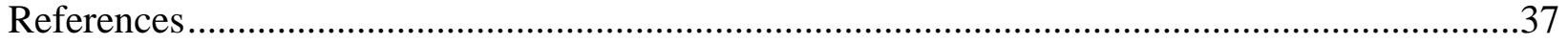




\section{Executive Summary}

Requirements for the color of rear turn signals differ between the standards set by the Economic Commission for Europe (ECE) and the United States standards. In the ECE standards, all rear turn signals are required to be amber, while in the United States, they can be either red or amber. This difference has led to questions about whether there are safety differences associated with each turn signal color. Consistent color coding of functions might facilitate recognition of the meaning of the signal, allowing a driver to respond more efficiently. It is also possible that, apart from color coding, an amber turn signal is also more conspicuous to a following driver amid a field of red tail and stop lamps. This might allow an amber turn signal to be recognized more quickly or confused less often with another rear signal.

The possible effects of turn signal color have been explored in a limited number of laboratory studies and crash analyses, with mixed results. Some laboratory studies suggest no effect on driver responses, while others cite advantages with amber lamps. Crash data analyses are similarly mixed. Examining rear-end collisions into turning vehicles, some reports have found no evidence of an effect of turn signal color on crash rates.

The following analysis revisits this issue with the benefit of a larger pool of crash data than before, and a logistic regression model that include many factors - such as driver age, gender, vehicle model, and vehicle age - that were not considered in previous analyses.

\section{Method}

This analysis examines the crash records of seven States to determine if there is an association between rear signal characteristics and the risk of a rear-end collision into a turning vehicle, taking into account a variety of other characteristics associated with the crash. To perform the analysis, detailed rear signal characteristics were determined for the top 50 vehicle models involved in crashes in Kentucky, Maryland, New Jersey, North Carolina, and Pennsylvania during 2003. For each model, the history of the rear signal configuration was examined over a 15-year window beginning with 1990, identifying rear signal color, lamp function configuration (i.e., whether a turn signal is separated from the stop lamp or tail lamp), light source (LED, tungsten filament), and optical characteristics.

The detailed lamp characteristics were combined with several other factors identified in the crash data in a stepwise logistic regression that modeled the odds of a rear-end collision while turning, merging, or changing lanes (i.e., a turn-signal-relevant maneuver), as a function of all of these factors. In a slight departure from previous crash analyses, the contrast group (used as the denominator of the odds ratio) in the first analysis was made of the striking vehicles from the same collisions. In a second analysis, the contrast group was made of rear-struck vehicles engaged in maneuvers that were not turn-signal relevant.

\section{Results and Discussion}

The first analysis found a reduction of between 3 and 28 percent in the odds of being the struck (versus striking) vehicle in a turn-signal-relevant maneuver when the 
vehicle was equipped with amber versus red turn signals. In addition, an effect of rear signal light source was also observed such that LED turn signals appeared to reduce crash odds between 33 and 92 percent. Although interesting, the latter result is based on a single vehicle model equipped with LED turn signals and cannot be readily generalized to all vehicles equipped with LED turn signals.

The second analysis found no association between turn signal color and the odds of being struck in a turn-signal-relevant maneuver, although turn-signal reflector optics (versus lens optics) were found to reduce the odds by between 5 and 51 percent. However, similar to the previously described LED result, this result is largely based on a few vehicle models equipped with turn signals with reflector optics, and generalization to all such lamps would be premature.

The differences between the two analyses indicate that selection of a contrast group can influence the effects observed. Because the contrast group in the first analysis is better insulated from the influence of rear signals, these results may be more accurate than those from the second analysis, implying that amber turn signals may be associated with lower odds of rear-end collision during turning, merging, or lane change maneuvers.

\section{Conclusions}

Although the analysis suggests that there may be a safety benefit associated with amber turn signals, it is unclear that turn signal color itself is completely responsible for the benefit. It is important to recognize that color is likely to be confounded with other factors that could also contribute to this effect. For example, although separation of functions was partly controlled for in this study, amber turn signals are usually separated from red stop and tail lamps. Also, requirements for the minimum and maximum candlepower of amber turn signals are 1.6 to 2.5 times greater than red turn signals. Further investigation of these other factors seems warranted before drawing the strong conclusion that turn signal color, by itself, is responsible for the observed differences. 


\section{Part I: The Association of Turn Signal Characteristics With Rear-End Collisions}

\section{Overview}

As vehicle turn signals evolved and became standardized over the last 100 years, differences arose in the European and United States standards (Moore \& Rumar, 1999). One particular difference is that European standards, governed by the Economic Commission for Europe (ECE), require rear turn signals to be exclusively amber (yellow). In the United States, Federal Motor Vehicle Safety Standard (FMVSS) 108 allows rear turn signals to be either amber or red. Thus, in Europe all rear turn signals are consistently colored amber, while in the United States, they are colored either amber or red.

One reason for the difference, ironically, stems from subjective tests of amber turn signals and recommendations made in the United States by the Vehicle Lighting Committee (VLC) of the Automobile Manufacturer's Association to the European organization of lighting experts, the Group de Travail-Bruxelles (GTB), at a meeting in 1960. The GTB, in turn, recommended the exclusive use of rear amber turn signals to the Europeans, and in 1967 the ECE made it a requirement. Meanwhile, U.S. manufacturers rejected their use based on unproven cost benefits (Maurer, 1980).

Presumably, the VLC demonstrations suggested that rear amber signals were more conspicuous than red, but detailed accounts of the demonstrations are not available. Based on human factors design principles, a case can easily be made that exclusive use of an amber rear turn signal would be preferred to a condition in which a turn signal could be either red or amber. At the perceptual level, an amber turn signal would be more easily distinguished from other red-colored rear lighting by the difference in color. Moreover, current lamp technology also necessitates the use of separate lamp compartments for differently colored lamps, ensuring that an amber turn signal is likely to be spatially offset from the red tail and brake lamps. Physical lamp separation also results in likely differences in the contrast between the off and on states of a lamp-there is likely to be less contrast between the off and on states of red turn signals that share compartments with red tail or brake lamps than for amber lamps in separate compartments. Photometric differences between amber and red signal intensity might also exist-FMVSS 108, for example, stipulates higher minimum and maximum intensities for yellow (amber) turn signals than for red (see Table 1). Actual intensity differences in the vehicle fleet could affect the relative conspicuity of each lamp (although one reason for the intensity difference was to offset the greater conspicuity of red signals). Unfortunately, there are no surveys available that accurately quantify such differences, but it is likely that differences exist. Finally, consistency in the meaning of the signal's color across the vehicle fleet could also speed recognition. Europeans, for example, might recognize rear-turn signals more quickly than Americans because they may benefit from the redundancy in color-coding the turn function (i.e., amber means turn, red means stop); in contrast, American drivers must recognize that a red signal could indicate a turning or braking vehicle and base their recognition on other signal cues (e.g., flashing lamps, asymmetric lamp illumination, non-energized center high-mounted stop lamp). 
Table 1.

Minimum and maximum candlepower values stipulated in FMVSS 108.

\begin{tabular}{|l|c|c|c|c|}
\hline \multirow{2}{*}{ Lamp } & & $\begin{array}{c}\text { Lighted } \\
\text { sections }\end{array}$ & \\
\cline { 2 - 5 } & $\mathbf{1}$ & $\mathbf{2}$ & $\mathbf{3}$ \\
\hline Red turn signal & $80 / 300$ & $95 / 360$ & $110 / 420$ \\
\hline Yellow (amber) turn signal & $130 / 750$ & $150 / 900$ & $175 / 1050$ \\
\hline
\end{tabular}

There have been a few laboratory studies examining the potential consequence of allowing two differently colored turn signals. Luoma, Flannagan, Sivak, Aoki, and Traube (1995) found that reaction time to a braking signal is shorter in the presence of amber turn signals compared to red. However, because this study blocked trials by signal color, it is important to recognize that the result may not be directly applicable to the American driving environment where a mixture of amber and red is always present. In the study, participants may have adopted a strategy whereby a brake detection response was solely dependent on the appearance of a red light within the amber turn-signal block. In the red turn-signal blocks, an alternative strategy that does not rely on color-coding would be necessary. The result suggests that European drivers might enjoy an advantage of color-coded function while American drivers do not. However, it does not suggest that that amber or red signals have a particular advantage in the context of a roadway environment where mixtures of both colors are present.

Post (1975) examined driver reaction time to respond to turn, brake, and hazard signals with a variety of lamp configurations. Although reaction time to amber hazard signals was generally shorter than to red, no difference was found in reaction time to turn signals or brake signals when a configuration employing amber signals was compared to one with red. Similarly, Mortimer and Sturgis (1974) found no significant effect of turn signal color on reaction time, although many of their results suggest shorter reaction times were observed with amber turn signals. Recognizing that as a red stimulus shifts toward the visual periphery it appears less saturated and more yellow, Sivak, Flannagan, Miyokawa, and Traube (2000) questioned the general utility of signal color coding in normal driving, where objects are presumably first detected in the periphery. They found that in daylight conditions, color discrimination declined at viewing angles of 10 degrees or more, suggesting that the usefulness of color might be somewhat limited in hastening detection.

As mentioned earlier, use of amber rear turn signals necessitates separation from the red stop lamps, resulting in both a spatial offset from the other rear signal lamps, and a likely boost in contrast between the off and on state of the signal. Relevant to the issue of lamp separation, a recent study reported by (Luoma, Sivak, \& Flannagan, 2006) examined whether rear-end collisions were influenced by separation of the brake lamp function from the other rear signal functions. They reasoned that braking activity for 
vehicles equipped with separated (dedicated) brake lamps would be easier to distinguish from other signal functions, especially at night when tail lamps are normally energized, reducing the contrast between the off and on states for combined lamps. The results suggest that dedicated stop lamps reduce rear-end collisions, although the authors caution that further examination of the data are warranted.

Beyond laboratory investigations, there has been just one analysis of crash data that investigated whether any differences in turn signal characteristics might be reflected in the crash record. Taylor and $\mathrm{Ng}$ (1981) examined insurance claim records involving rear-end collisions. They compared the proportion of turning crashes involving struck lead vehicles equipped with red turn signals to those equipped with amber turn signals. To account for exposure differences, the proportions were compared to rear-end collisions that did not involve turning vehicles. The analysis found no difference in rearend crash rates between vehicles equipped with amber and red turn signals. Although the study attempted to analyze factors like driver age, gender, vehicle size, model year, light conditions, and at-fault driver status, the sample size of 1440 vehicles (386 amber; 1053 red) may have been insufficient to observe a clear effect. A power analysis that assumes a 6-percent difference in proportions of red lamps involved in turning versus non-turning crashes (with proportionally similar crash distribution) suggests that nearly 3,000 crashes would be needed to detect such a difference.

All of the vehicles compared in the preceding crash study pre-date the introduction of center high-mounted stop lamps (CHMSL), introduced in the 1986 model year. One effect of the introduction of CHMSL was an estimated reduction of rear-end collisions by about 4.3 percent (Kahane \& Hertz, 1998). One might argue that, in the years prior to the introduction of CHMSL, red rear turn signals might have been more confusable with rear brake signals and possibly led to more rear-end collisions during turning. Once the CHMSL was introduced, the difference between a turning and a braking vehicle may have become clearer to following drivers. It seems that now, there is perhaps even less chance that a difference between turn signal color might lead to a rear-end collision.

It is important to keep in mind that the experimental studies cited above do not present subjects with conditions that are directly comparable to the circumstances in which a crash occurs. For example, studies that address questions about unique colorcoding of rear signal function (e.g., Luoma, Flannagan, Sivak, Aoki, \& Traube, 1995; Mortimer \& Sturgis, 1974) do not resemble the existing U.S. and Canadian crash environments where there is a mixture of both red and amber turn signals-red could signal either a turn or braking, a turn could be signaled with either an amber or red flashing lamp, however amber would mean a turn. While there may be some benefit for all vehicles to use amber rear turn signals, domestic crash data cannot directly assess this benefit. Instead, any differences found in crash rates between the two colors are most likely attributable to differences that make one more conspicuous than another.

\section{Signal characteristics related to crash risk}

In the few crash analyses that attempt to address the potential differences between red and amber turn signals there is little discussion about what mechanisms might lead a driver to be more likely to strike a vehicle equipped with a red turn signal and less likely to strike a vehicle equipped with an amber turn signal. Indeed, it is often implied that 
amber turn signals are more conspicuous than red. Perhaps amber turn signals are noticed earlier than red turn signals and provide drivers with more time to anticipate the movements of a forward vehicle.

On the other hand, perhaps drivers mistake a red turn signal for a brake signal. Unfortunately, this would not explain how confusion between a turn and a brake signal would lead to a rear-end collision. That is, if a driver sees a turn signal and mistakes it for a brake signal, it is reasonable to assume that the normal response would be to brake, perhaps inappropriately. If a driver sees a brake signal, and mistakes it for a turn signal, it is conceivable that the driver might fail to brake and strike the forward vehicle. However this failure could easily occur for either amber or red turn signal equipped vehicles. Unless there is a scenario in which (from the following driver's perspective) a turn signal indicates that a rapid deceleration is imminent, and in which a brake signal does not indicate an imminent deceleration, it is difficult to see how the confusion of one signal for another would lead to a rear-end collision.

There are a few scenarios in which something like this is plausible. As vehicles approach a lane closure on a limited access highway, there may be both braking and signaling of a merge into an adjacent lane. If a driver following behind another vehicle in an adjacent lane, mistakes the forward vehicle's signal as braking instead of merging, a rear-end collision could result when the forward vehicle encroaches into the following driver's lane (shown in Figure 1). In another scenario, it is plausible that as a vehicle transitions from a high speed to a lower speed, braking may occur over an extended duration in order to decelerate in a smooth fashion. From the perspective of a following vehicle, in this context the forward vehicle's brake lamp does not signal an imminent deceleration. However, if a turn signal is energized, a following vehicle may well anticipate that a stronger deceleration is about to happen (in order to make a turn at a comfortable speed). In this scenario, a failure to detect the turn signal may impede the following driver's ability to anticipate the deceleration, resulting in a rear-end collision (shown in Figure 2). 


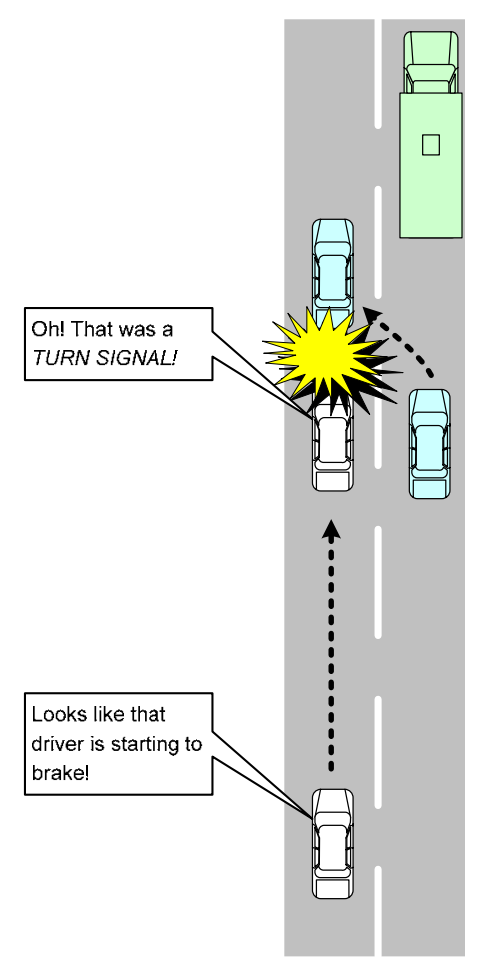

Figure 1. A crash scenario in which a turn signal is mistaken for a brake signal and leads to a rear-end collision. 


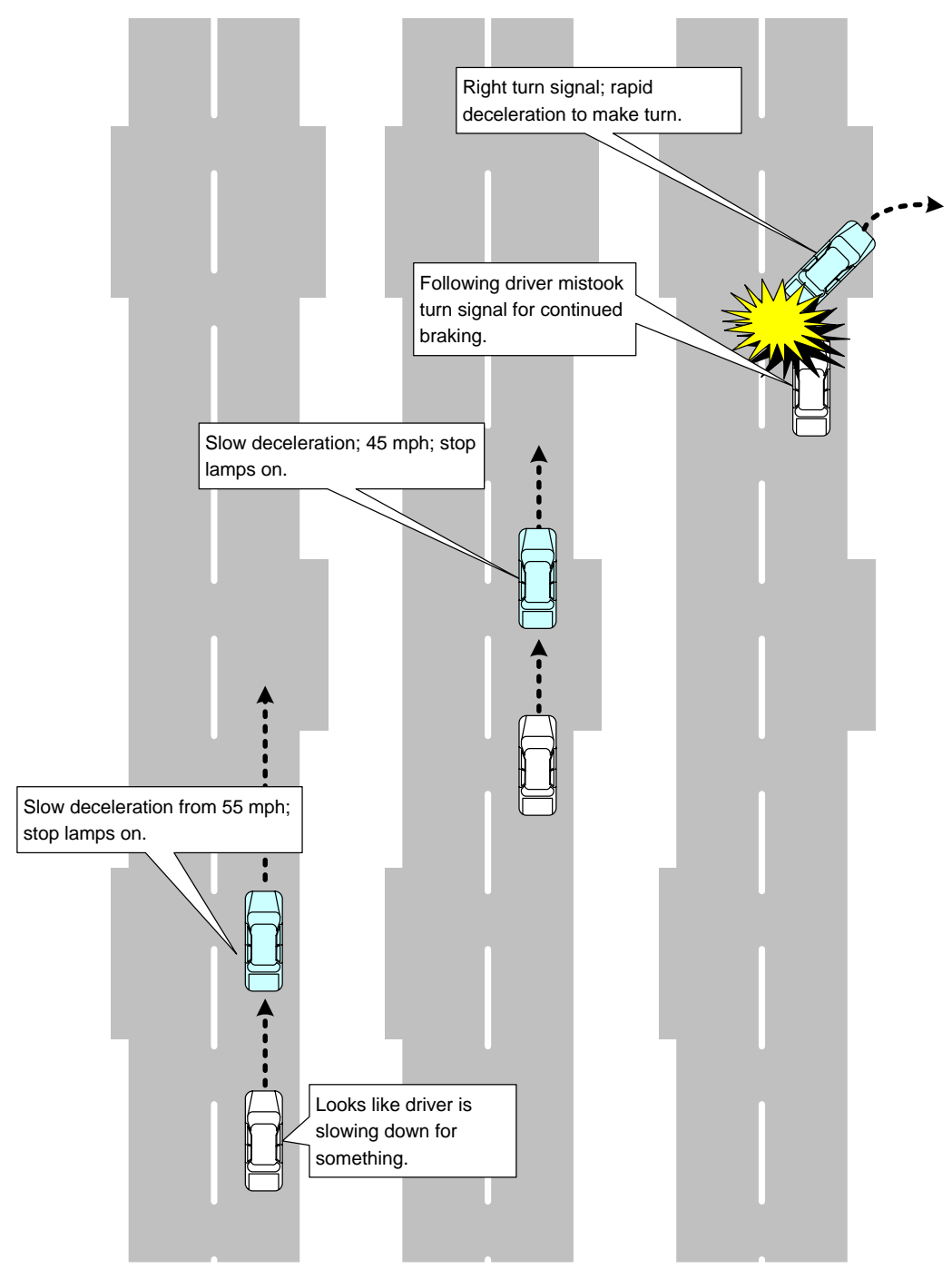

Figure 2. Crash scenario in which a forward vehicle initiates a gentle deceleration before turning. In this example, the turn signal could help a following driver identify where the forward vehicle will initiate a sharp deceleration in order to execute a turn.

\section{General analysis approach}

Throughout this report, data were analyzed using stepwise logistic regression procedures (the LOGISTIC procedure, in SAS). In this approach, the odds of a crash are modeled using various characteristics of a driver-vehicle configuration (independent factors). In this analysis, there is particular interest in turn-signal lamp characteristics, but, as will be seen, other factors may also influence the odds of a crash. The stepwise analysis proceeds by adding factors to a regression model one-by-one. Each factor is drawn from the pool of candidate factors until no factors remain in the pool that can improve the predictive power of the model. The resulting model contains only those factors that significantly improve prediction of the dependent variable. 
For this analysis, the dependent variable is the odds of a crash likely to be associated to a driver's response to a rear turn signal - that is, a relevant crash. To obtain the odds of a relevant crash, non-relevant crashes are also required. The resulting odds are given by:

$$
\text { odds }=\left(\frac{\text { frequency of relevant crashes }}{\text { frequencyof non - relevant crashes }}\right)
$$

Logistic regressions actually model the natural log of the odds of an event as a function of multiple independent factors, providing estimates of the influence each factor has on the resulting odds. The "event" in this analysis is the odds of a rear-end collision into a vehicle that is either turning or changing lanes (and, presumably, influenced by turn signal characteristics). The question addressed in the analysis is whether these odds are smaller for lead vehicles equipped with amber turn signals than they are for lead vehicles equipped with red turn signals.

As mentioned above, calculation of odds also requires counting the target vehicle's involvement in non-relevant crashes. Non-relevant crashes are crashes that are not affected by the variable of interest (i.e., turn signal color) that can serve as a kind of measure of general vehicle exposure. The crash analyses cited earlier determined nonrelevant crash frequency using rear-end crashes between vehicles in which turning or lane change maneuvers were not involved (shown in Figure 3). More importantly, these nonrelevant crashes were classified as either red or amber, based on the rear signal configuration of the lead (i.e., struck) vehicle. One critique of using the lead vehicle is that it is possible that a rear signal configuration that reduces rear-end collisions in lane change, merge, and turning scenarios might also produce side-benefits that reduce rearend collisions in other circumstances (i.e., non-relevant) as well. If lamp characteristics influence both relevant and non-relevant crash characteristics in the same way, the resulting odds ratio (relevant/non-relevant) may not show any influence. In this report, an alternative calculation of the non-relevant crash is provided in which non-relevant crashes are based on the rear-signal configuration of the striking vehicle. Presumably, the drivers in striking vehicles are not influenced by the rear signal characteristics of their own vehicles. 

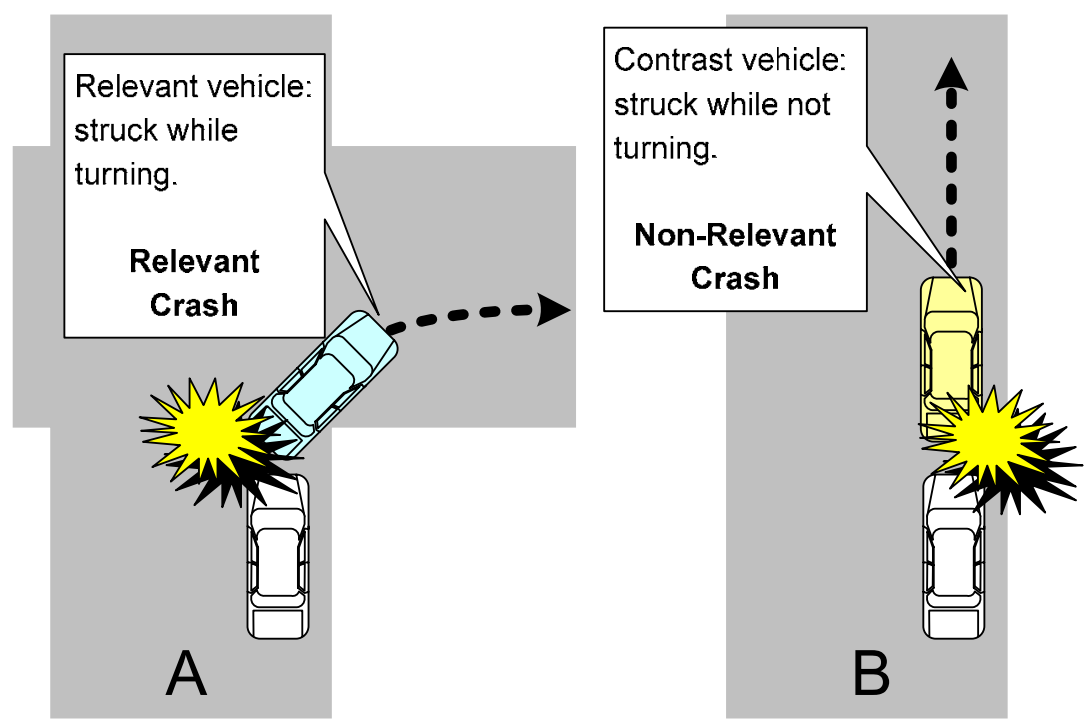

Figure 3. Crash scenarios in which the turn signal characteristics are relevant are illustrated in A; crash scenarios in which turn signal characteristics are non-relevant are illustrated in B.

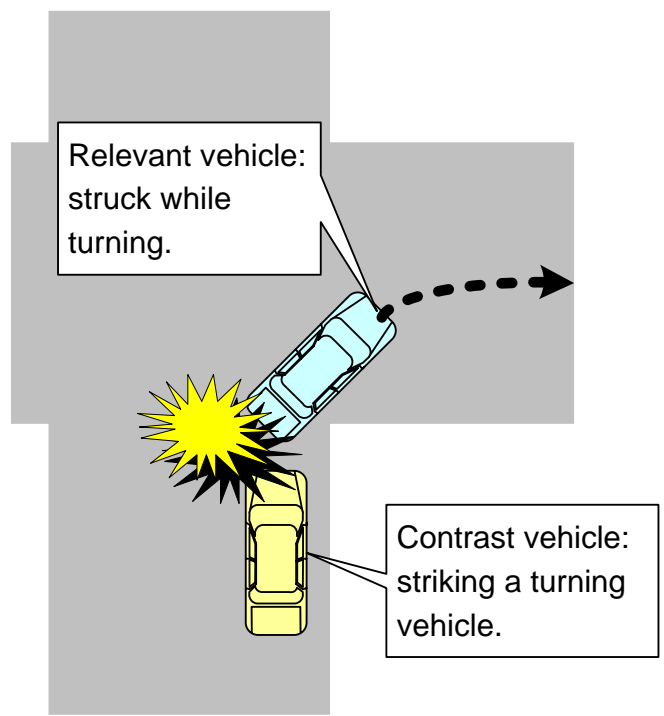

Figure 4. As an alternative to $\mathrm{B}$ in Figure 3, odds ratios were based on the signal characteristics of the struck versus striking vehicle in rear-end collisions involving turning vehicles. 


\section{Method}

\section{Vehicle Selection and Rear Signal Database Development}

As described in the analysis approach, an important component of the logistic regression analysis is the association of rear signal lamp characteristics to the odds of a crash. In the ideal situation, a complete set of rear signal characteristics would be determined for each vehicle involved in a rear-end collision and factored into the regression. Unfortunately, there are no available reference sources that describe a vehicle's rear signal configuration throughout its production history.

Alternative vehicle selection strategies were considered with the aim of producing a sufficiently large vehicle sample to ensure sufficient power in the crash analysis so that even modest influences of signal lamp characteristics could be determined. In prior crash analyses (for example, Luoma et al., 2006; Taylor \& Ng, 1981), researchers selected companion vehicle pairs with known differences in signal color (or other attributes) and made direct comparisons between them. These vehicle selections appear to have been made in an ad hoc fashion - no reference sources exist that provide sufficient description of vehicle rear signal configurations to support selection. Without such a reference, determination of the rear signal characteristics of a vehicle requires individually researching the signal characteristics of each vehicle model that might be included in a crash analysis. Because rear signal characteristics are also an element of vehicle styling, they change as a vehicle's body style evolves over time. Thus it is necessary to trace the rear signal production history of each vehicle. To compile this information, it was necessary to gather data from several sources. These included dealerships, parts catalogs, promotional brochures, owners groups, and contacts from within the auto companies. Since it was not feasible to conduct an exhaustive survey of all vehicle makes and models, limits were placed on the models and model-years included in the survey.

Model years were selected to span the years 1990 to 2005, and models were selected to include only the top 50 models found in an initial survey of five State crash datasets from the calendar year (CY) 2003. Each dataset included the vehicle identification number (VIN) for each vehicle involved in a collision. The VIN was used to determine the make, series name (model), and model year of each vehicle by decoding it using VINDICATOR 2005 software, developed by the Highway Loss Data Institute. Differences were found among the selected State crash datasets in the proportion of involved vehicles that were successfully decoded (shown in Table 2). The North Carolina datasets have the fewest decoding errors (around 8\%); while Florida, Maryland, and New Jersey have the most (around 40\%). 
Table 2.

Proportion of the total number of vehicles in each State dataset that could not be successfully decoded by VINDICATOR software.

\begin{tabular}{|l|c|c|c|c|c|}
\hline State & Year & $\begin{array}{c}\text { Total } \\
\text { Crashes }\end{array}$ & $\begin{array}{c}\text { Total } \\
\text { Vehicles }\end{array}$ & $\begin{array}{c}\text { Total } \\
\text { Decoding } \\
\text { Errors }\end{array}$ & Percent \\
\hline Florida & 2003 & 243,294 & 478,182 & 192,236 & $40.2 \%$ \\
\hline Kentucky & 2003 & 154,075 & 278,531 & 48,316 & $17.4 \%$ \\
\hline Maryland & 2003 & 109,098 & 202,808 & 78,200 & $38.6 \%$ \\
\hline Michigan & 2004 & 374,446 & 637,539 & 194,044 & $30.4 \%$ \\
\hline New Jersey & 2002 & 324,053 & 606,502 & 252,981 & $41.7 \%$ \\
\hline New Jersey & 2003 & 319,980 & 609,439 & 246,656 & $40.5 \%$ \\
\hline North Carolina & 2002 & 285,135 & 448,162 & 33,702 & $7.5 \%$ \\
\hline North Carolina & 2003 & 270,224 & 470,561 & 41,197 & $8.8 \%$ \\
\hline Pennsylvania & 2003 & 139,402 & 230,413 & 25,742 & $11.2 \%$ \\
\hline
\end{tabular}

State crash datasets were selected based on the volume of crashes reported, geographical distribution, inclusion of VIN data, and use of coding conventions that would allow sufficient distinction of crash scenario details to enable determination of relevant and non-relevant crashes, vehicle roles (striking/struck), and other factors detailed in the crash section of this report. The resulting compilation of crash frequency of vehicle models is shown in Table 3, sorted in descending order by frequency. 
Table 3.

Counts of the most frequently occurring vehicle models in five State crash datasets from CY 2003 collapsed over model years.

\begin{tabular}{|c|c|c|c|c|c|c|c|}
\hline KY & MD & NC & NJ & PA & Make & Series & Totals \\
\hline 4,127 & 6,251 & 17,864 & 12,027 & 3,793 & HONDA & ACCORD 4D & 51,958 \\
\hline 7,981 & 6,980 & 12,850 & 11,053 & 3,423 & TOYOTA & CAMRY 4D 2WD & 51,173 \\
\hline 4,677 & 5,515 & 7,311 & 7,817 & 2,506 & TOYOTA & COROLLA SEDAN 2WD & 35,649 \\
\hline 5,882 & 3,453 & 9,234 & 7,340 & 4,462 & FORD & TAURUS 4D & 35,206 \\
\hline 1,698 & 2,514 & 6,185 & 6,567 & 2,189 & HONDA & CIVIC 4D & 23,096 \\
\hline 2,603 & 2,898 & 5,975 & 5,058 & 1,859 & NISSAN & ALTIMA 4D & 22,477 \\
\hline 2,852 & 2,505 & 5,291 & 5,972 & 3,240 & FORD TRUCK & EXPLORER 4D 4X4 & 20,770 \\
\hline 3,106 & 3,521 & 5,213 & 2,738 & 1,474 & FORD & LTD/CROWN VICTORIA 4D & 19,954 \\
\hline 1,860 & 2,218 & 4,771 & 5,242 & 1,678 & NISSAN & 810/MAXIMA SEDAN & 18,392 \\
\hline 3,655 & 2,566 & 3,695 & 2,594 & 3,788 & CHEVROLET & CAVALIER 2D & 18,354 \\
\hline 2,310 & 1,988 & 4,612 & 5,835 & 2,595 & JEEP & GRAND CHEROKEE 4D 4X4 & 18,191 \\
\hline 1,733 & 2,174 & 4,821 & 3,650 & 1,231 & NISSAN & SENTRA 4D & 16,895 \\
\hline 1,711 & 1,826 & 4,071 & 3,717 & 2,184 & SATURN & SL 4D & 16,504 \\
\hline 2,722 & 1,255 & 5,530 & 1,925 & 1,186 & FORD & MUSTANG 2D & 16,187 \\
\hline 2,569 & 2,610 & 3,721 & 2,161 & 2,586 & CHEVROLET & CAVALIER 4D & 16,095 \\
\hline 1,182 & 1,894 & 4,173 & 4,179 & 1,443 & HONDA & CIVIC 2D COUPE & 15,827 \\
\hline 3,510 & 1,090 & 5,069 & 1,460 & 1,093 & FORD TRUCK & RANGER PICKUP 4X2 & 15,380 \\
\hline 2,614 & 1,112 & 4,727 & 1,772 & 1,020 & FORD TRUCK & F150 PICKUP 4X2 & 14,457 \\
\hline 2,550 & 1,022 & 4,032 & 2,133 & 2,062 & PONTIAC & GRAND AM 4D & 13,484 \\
\hline 3,730 & 834 & 4,569 & 1,088 & 1,011 & CHEVY TRUCK & S10 PICKUP 4X2 & 13,285 \\
\hline 1,545 & 1,336 & 3,666 & 2,865 & 1,583 & DODGE TRUCK & GRAND CARAVAN 2WD & 12,985 \\
\hline 1,886 & 1,556 & 3,461 & 2,053 & 1,810 & FORD & ESCORT 4D & 12,952 \\
\hline 1,648 & 1,073 & 3,389 & 3,464 & 1,602 & FORD TRUCK & WINDSTAR VAN & 12,823 \\
\hline 2,170 & 909 & 3,973 & 2,141 & 1,481 & BUICK & LESABRE 4D & 12,646 \\
\hline 2,644 & 1,174 & 3,373 & 1,797 & 1,829 & CHEVROLET & LUMINA 4D & 12,464 \\
\hline 1,556 & 1,626 & 2,940 & 2,255 & 1,997 & DODGE & NEON 4D & 12,181 \\
\hline 2,868 & 1,343 & 2,950 & 2,240 & 2,150 & CHEVY TRUCK & T10 BLAZER 4D 4X4 & 12,029 \\
\hline 1,218 & 1,517 & 4,381 & 2,119 & 866 & MAZDA & 626 SEDAN & 11,950 \\
\hline 1,467 & 999 & 2,685 & 3,428 & 732 & LINCOLN & TOWN CAR/CONT. 4D & 11,822 \\
\hline 1,757 & 819 & 3,245 & 2,226 & 1,673 & BUICK & CENTURY 4D & 11,550 \\
\hline 740 & 1,076 & 3,581 & 3,209 & 855 & HONDA & ACCORD 2D & 11,481 \\
\hline 1,667 & 1,244 & 2,906 & 2,994 & 2,000 & JEEP & CHEROKEE 4D 4X4 & 11,398 \\
\hline 1,808 & 1,581 & 2,776 & 2,227 & 1,371 & CHEVROLET & MALIBU 4D & 11,389 \\
\hline 1,280 & 1,208 & 2,554 & 2,491 & 1,606 & DODGE TRUCK & CARAVAN VAN 2WD & 11,313 \\
\hline 1,356 & 934 & 2,264 & 2,648 & 867 & MERCURY & MARQUIS/G. MARQ. 4D & 11,282 \\
\hline 1,897 & 877 & 3,302 & 1,910 & 796 & CADILLAC & DEVILLE 4D FWD & 10,870 \\
\hline 697 & 1,156 & 3,121 & 2,662 & 955 & MITSUBISHI & GALANT 4D 2WD & 10,730 \\
\hline 1,739 & 805 & 3,020 & 1,821 & 1,428 & DODGE & INTREPID 4D & 10,266 \\
\hline 1,291 & 777 & 2,154 & 2,605 & 1,304 & MERCURY & SABLE 4D & 9,536 \\
\hline 1,289 & 477 & 3,215 & 978 & 308 & FORD TRUCK & F150 SUPER PU 4X2 & 9,439 \\
\hline 910 & 1,117 & 2,346 & 1,967 & 1,185 & FORD & FOCUS 4D & 9,094 \\
\hline 2,316 & 430 & 3,557 & 541 & 515 & CHEVY TRUCK & 10/1500 PU $1 / 2 \mathrm{~T}$ & 8,852 \\
\hline 1,818 & 540 & 3,187 & 914 & 668 & CHEVROLET & CAMARO 2D & 8,826 \\
\hline 1,406 & 566 & 3,164 & 805 & 409 & FORD TRUCK & RANGER SUPER PU $4 X 2$ & 8,638 \\
\hline 1,448 & 732 & 2,471 & 1,334 & 1,395 & FORD & ESCORT 2D & 8,631 \\
\hline 388 & 187 & 3,275 & 268 & 87 & FORD TRUCK & EXPLORER 4D 4X2 & 8,024 \\
\hline 1,521 & 715 & 2,354 & 1,416 & 952 & FORD & CONTOUR 4D & 7,936 \\
\hline 906 & 628 & 2,372 & 1,589 & 767 & MITSUBISHI & ECLIPSE 2D 2WD & 7,871 \\
\hline 825 & 896 & 1,215 & 2,423 & 1,210 & HYUNDAI & ELANTRA 4D & 7,853 \\
\hline 1,801 & 503 & 2,116 & 1,240 & 1,022 & PONTIAC & GRAND PRIX 4D & 7,720 \\
\hline 1,078 & 861 & 2,319 & 1,237 & 1,114 & DODGE & STRATUS 4D & 7,669 \\
\hline
\end{tabular}


Using this list as a basis, data on each vehicle's rear signal lighting configuration were compiled in a supplemental database that could be cross-referenced using decoded VIN information from the crash tables. For each vehicle make and series name, the rear signal lamp configuration was described using the following principal data fields (summarized in Table 4:

- Start/End Model Years (1990-2005). Within a model's lifetime, styling changes occur that frequently result in changes in a rear signal lamp's configuration. This data field identifies the spanning years for a given lamp configuration.

- Turn Signal Color (Red, Amber). This field identifies the color of the energized turn signal.

- Turn Signal Lens Color (Clear/Tinted). Clear signal lenses admit more light than tinted lenses potentially affecting daytime visibility.

- Turn Signal Source (Tungsten/LED). Although most vehicles are equipped with tungsten-filament bulbs, some newer vehicles are beginning to appear equipped with LED turn signal sources. There is some evidence that the rapid rise time of an LED lamp enhances a driver's response (Sivak, Flannagan, Sato, Traube, \& Aoki, 1994).

- Turn Signal Optics (Lens/Reflector). A signal lamp can distribute light using a faceted lens or using a smooth lens and faceted reflector combination.

- Rear Signal Separation Code. This code identified how the stop, turn, and tail (presence) lamps were distributed among the separate lamp compartments on the rear of the vehicle. In the code, separate compartments were indicated by comma separations; combined functions within a compartment were indicated using slashes to separate the codes.

The lens color, source, and optics of brake and tail lamps were also identified during this process, although these attributes were not specifically investigated in the turn-signal analyses. Additional fields were used to flag exceptions, record notes, identify vehicles equipped with rear fog lamps, and reference photographs of sample lamps. An example data-entry screen is shown in Figure 5. 
Table 4.

Definition of supplemental database fields used to describe rear signal configuration.

\begin{tabular}{|c|c|c|c|}
\hline Grouping & Field Name & Values & Description \\
\hline \multirow{2}{*}{$\begin{array}{l}\text { Model Year } \\
\text { Span }\end{array}$} & Start Year & 4-digit year & \multirow{2}{*}{$\begin{array}{l}\text { Many vehicles change signal lamp } \\
\text { characteristics along with other } \\
\text { styling changes. }\end{array}$} \\
\hline & End Year & 4-digit year $>$ start year & \\
\hline \multirow[t]{4}{*}{ Turn Signal } & Color & Red, Amber & \\
\hline & Lens Color & Clear, Tinted & \\
\hline & Source & Tungsten, LED & \\
\hline & Optics & Lens, Reflector & \\
\hline \multirow[t]{3}{*}{ Brake Signal } & Lens Color & Clear, Tinted & \\
\hline & Source & Tungsten, LED & \\
\hline & Optics & Lens, Reflector & \\
\hline \multirow[t]{3}{*}{ Tail Signal } & Lens Color & Clear, Tinted & \\
\hline & Source & Tungsten, LED & \\
\hline & Optics & Lens, Reflector & \\
\hline \multirow[t]{10}{*}{$\begin{array}{l}\text { Rear Signal } \\
\text { Separation }\end{array}$} & Configuration & e.g., S/T/TS, T & $\begin{array}{l}\text { In the example, } \mathrm{S}=\text { Stop Lamp, } \mathrm{T}= \\
\text { tail lamp (presence), and TS }=\text { Turn } \\
\text { Signal. Separate lamp compartments } \\
\text { are separated by commas. The } \\
\text { example code identifies a rear-signal } \\
\text { in which one compartment has } \\
\text { combined stop, tail, and turn signal } \\
\text { functions, and a separate } \\
\text { compartment containing only the tail } \\
\text { lamp. }\end{array}$ \\
\hline & & $\mathrm{S}, \mathrm{T}, \mathrm{TS}$ & All lamp functions separate. \\
\hline & & $\mathrm{S} / \mathrm{T} / \mathrm{TS}$ & All lamp functions combined. \\
\hline & & $\mathrm{S} / \mathrm{T}, \mathrm{TS}$ & $\begin{array}{l}\text { Stop and Tail combined, Turn Signal } \\
\text { separate. }\end{array}$ \\
\hline & & $\mathrm{S} / \mathrm{T}, \mathrm{T}, \mathrm{TS}$ & $\begin{array}{l}\text { Stop and Tail combined, Tail and } \\
\text { Turn Signal separate. }\end{array}$ \\
\hline & & $\mathrm{S} / \mathrm{T}, \mathrm{T} / \mathrm{TS}$ & $\begin{array}{l}\text { Tail combined with separated Stop } \\
\text { and Turn Signal. }\end{array}$ \\
\hline & & $\mathrm{S} / \mathrm{T} / \mathrm{TS}, \mathrm{T}$ & $\begin{array}{l}\text { All functions combined in one } \\
\text { compartment, separate compartment } \\
\text { for Tail. }\end{array}$ \\
\hline & & $\mathrm{S} / \mathrm{TS}, \mathrm{T}$ & $\begin{array}{l}\text { Stop and Turn Signal combined, Tail } \\
\text { lamp separate. }\end{array}$ \\
\hline & & $\mathrm{S} / \mathrm{T}, \mathrm{S} / \mathrm{T}, \mathrm{TS}$ & $\begin{array}{l}\text { Two compartments with Stop and } \\
\text { Tail combined; Turn Signal separate. }\end{array}$ \\
\hline & & $\mathrm{S} / \mathrm{T} / \mathrm{TS}, \mathrm{S} / \mathrm{T}$ & $\begin{array}{l}\text { Stop, Tail, and Turn Signal } \\
\text { combined, Stop and Tail combined. }\end{array}$ \\
\hline
\end{tabular}




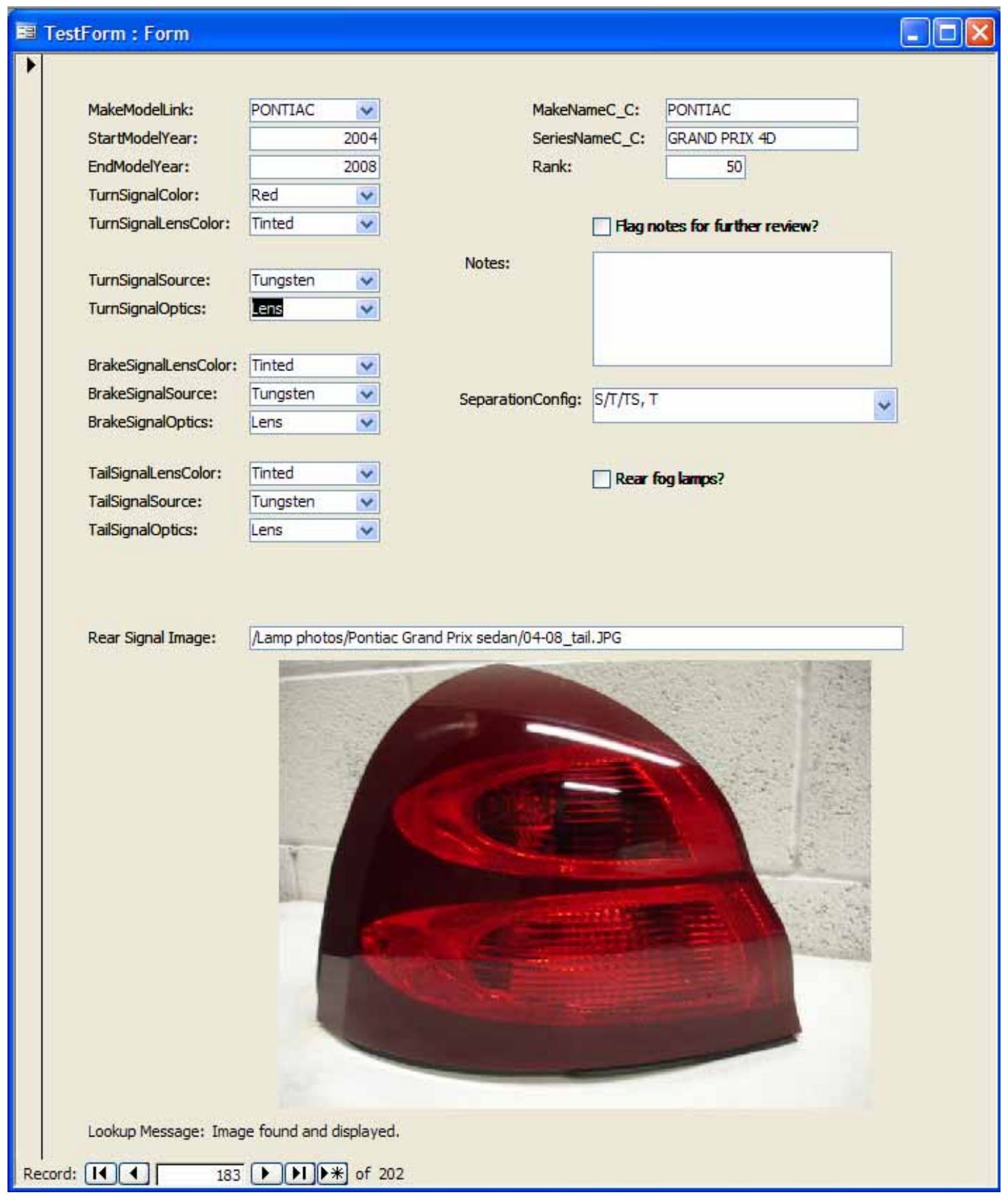

Figure 5. Microsoft Access data entry form used to compile lamp characteristics of rear signal lamps. 


\section{Crash Scenario Selection and Data Processing}

Crash records were initially obtained for Florida, Kentucky, Maryland, North Carolina, New Jersey, and Pennsylvania for CY2003 and Michigan CY2004. The analysis was later expanded to include data from CY2002 for New Jersey and North Carolina based on a power analysis that estimated the number of cases required to observe risk differences as small as 9 percent.

The VIN data from each State dataset was initially linked to the VINDICATOR 2005 dataset to produce a standard labeling for vehicle makes and series names. Each of the resulting State datasets was then examined to determine the extent of data loss that occurred as a consequence of VIN-decoding errors. Datasets varied in the accuracy with which the VIN is transcribed. Common reasons for a decoding error include: the recorded VIN is missing, is invalid, or has failed to match a series/model key in the VINDICATOR dataset. As shown in Table 2, the Florida and New Jersey datasets had the largest proportion of vehicle identification errors (about 40\%); the North Carolina datasets had the fewest identification errors ( 8 to $9 \%$ ).

Relevant and Non-Relevant Crashes. As described earlier, the key dependent measure in the logistic regression is an odds ratio that relates the odds of a relevant crash with respect to a non-relevant crash. In this analysis, relevant crashes used the following selection criteria:

- The crash was identified as a rear-end collision.

- Only two vehicles were involved in the collision. This was done to simplify the crash configuration so that each vehicle's role could be unambiguously determined.

- The lead (i.e., struck) vehicle was either described as changing lanes, merging, or turning. It is plausible to assume that the lead vehicle may have been using a turn signal prior to the maneuver, although it is clear that drivers often omit use of turn signals.

- One vehicle's impact location was identified as in the rear (struck); and the other vehicle's impact location was identified as in the front (striking). This restriction served to exclude crashes where both crash participants are identified as occurring in the same location. For this analysis, the characteristics of the lead vehicle's rear signals served as the basis of the relevant dataset.

In the logistic regression, the non-relevant dataset serves as a kind of exposure control helping to normalize the relevant crash data to the varying concentrations of vehicles on the roadway. Selection of a suitable basis for this control sample can introduce artifacts into an analysis that can obscure or even bias an outcome. For example, suppose the relationship between driver age (young/old) and risk of involvement in rear-end collisions were evaluated using another collision type-for example, single-vehicle road departure (SVRD) - as an exposure control. Systematic differences in the SVRD crash sample - especially related to a factor of interest, driver age - could lead to an erroneous conclusion.

In this analysis, two non-relevant datasets were developed. The first dataset used the same crash criteria employed in the relevant crash selections with the exception that the rear-signal characteristics were determined for the striking vehicle. It is thus assumed 
that the rear signal characteristics of a striking vehicle play little role in these crashes and can serve as a reasonable measure of exposure. While there may be significant demographic differences between striking and struck drivers in this scenario, it is assumed that such differences are not systematically related to a driver's signal lamp characteristics.

The second non-relevant dataset was developed based on the analyses reported by Taylor and $\mathrm{Ng}$ (1981). In their analyses, non-relevant crashes were identified as rear-end collisions that did not involve turns, merges, or lane change maneuvers. Importantly, the authors identified the characteristics of the lead (struck) vehicle in these crashes. One potential difficulty with this approach is that if the turn signal characteristic of interestamber versus red-somehow influences the salience of other rear signals, we might find that other rear-end collision types (i.e., those not necessarily involving turns, merges, or lane changes) are also affected. In this case, there is a chance that an amber turn signal might reduce both the relevant and non-relevant crashes. This would diminish the likelihood of observing an effect. The selection criteria for this dataset, referred to as non-turning crashes, applied the same selection criteria as described for the Relevant crash selection except that the lead vehicle maneuver was not described as turning, merging, or changing lanes.

Table 5 provides a breakdown of the rear-end crash scenarios and their distribution within each State dataset. For most of the States, non-turning crashes make up between 13 and 18 percent of all reported crashes; the relevant crashes make up between 1 and 2 percent of all crashes. Notably, Florida appears to be an outlier with proportionally less than half of the crash percentages found in the other State datasets. It is currently unclear what the basis of this difference is.

Table 5.

Frequency of all crashes and rear-end crashes involving two vehicles in which the struck vehicle was not turning, merging, or changing lanes, and two vehicles in which the struck vehicle was turning, merging, or changing lanes.

\begin{tabular}{|c|c|c|c|c|c|c|}
\hline State & Year & $\begin{array}{c}\text { Total } \\
\text { Crashes }\end{array}$ & $\begin{array}{c}\text { Two-Vehicle } \\
\text { Rear-End } \\
\text { Non-Turning } \\
\text { (Non-Relevant } \\
\text { Crashes) }\end{array}$ & Percent & $\begin{array}{l}\text { Two-Vehicle } \\
\text { Rear-End Turn, } \\
\text { Merge, Lane } \\
\text { Change } \\
\text { (Relevant } \\
\text { Crashes) }\end{array}$ & Percent \\
\hline Florida & 2003 & 243,294 & 17,991 & $7.4 \%$ & 1,287 & $0.5 \%$ \\
\hline Kentucky & 2003 & 154,075 & 27,517 & $17.9 \%$ & 2,219 & $1.4 \%$ \\
\hline Maryland & 2003 & 109,098 & 17,148 & $15.7 \%$ & 1,131 & $1.0 \%$ \\
\hline Michigan & 2004 & 374,446 & 62,433 & $16.7 \%$ & 4,552 & $1.2 \%$ \\
\hline North Carolina & 2002 & 285,135 & 50,346 & $17.7 \%$ & 4,408 & $1.6 \%$ \\
\hline North Carolina & 2003 & 270,224 & 47,674 & $17.6 \%$ & 4,427 & $1.6 \%$ \\
\hline New Jersey & 2002 & 324,053 & 59,017 & $18.2 \%$ & 6,243 & $1.9 \%$ \\
\hline New Jersey & 2003 & 319,980 & 58,872 & $18.4 \%$ & 6,514 & $2.0 \%$ \\
\hline Pennsylvania & 2003 & 139,402 & 18,279 & $13.1 \%$ & 1,144 & $0.8 \%$ \\
\hline
\end{tabular}


Once the crash records of the two rear-end scenarios were selected (relevant and non-relevant), the VIN data of both the striking and struck vehicles in the turning/merging/lane changing rear-end collisions were matched to vehicles contained in the Rear Signal Database. Note that the Rear Signal Database contains only the most frequently occurring 50 vehicles among five CY 2003 State crash datasets (shown in Table 3). With this restriction, the overall vehicle sample size becomes smaller. The resulting breakdown by State is shown in the first two data columns of Table 6. The total vehicle count used in this analysis is approximately 13 times greater than included in the Taylor and Ng study (1981). The first two data columns of Table 7 shows the same data, collapsing over States and showing the breakdown by turn signal color and driver role in the collision.

A similar selection procedure was used to create a dataset comprised of rear-end crashes not involving turning, merging, or lane change maneuvers. This dataset served as a second non-relevant crash reference, similar to the striking drivers previously described. The resulting crash breakdown by state is shown in the third data column of Table 6, and the crash breakdown by turn signal color is shown in the third column of Table 7. An overview of the data processing steps is shown in Figure 6.

Table 6.

Crash counts by State and driver role in collision for each rear-end collision type.

\begin{tabular}{|c|c|c|c|}
\hline & \multicolumn{2}{|c|}{$\begin{array}{c}\text { Rear-end collisions while turning, } \\
\text { merging, or changing lanes }\end{array}$} & $\begin{array}{l}\text { Rear-end collisions not involving } \\
\text { turning, merging, or changing lanes }\end{array}$ \\
\hline State & $\begin{array}{c}\text { Struck } \\
\text { (Rear Impact) }\end{array}$ & $\begin{array}{c}\text { Striking } \\
\text { (Front Impact) }\end{array}$ & $\begin{array}{c}\text { Struck } \\
\text { (Rear Impact) }\end{array}$ \\
\hline Florida & 361 & 285 & 4,904 \\
\hline Kentucky & 812 & 676 & 10,525 \\
\hline Maryland & 496 & 421 & 7,047 \\
\hline Michigan & 1,478 & 1,276 & 19,900 \\
\hline North Carolina & 3,163 & 2,756 & 36,289 \\
\hline New Jersey & 3,398 & 2,839 & 31,098 \\
\hline Pennsylvania & 382 & 336 & 5,972 \\
\hline Total & 10,090 & 8,589 & 115,735 \\
\hline
\end{tabular}

Table 7.

Breakdown of crash frequencies by signal lamp color, role in crash, and for each rear-end collision type.

\begin{tabular}{|l||c|c|c|c|}
\hline \multirow{2}{*}{} & \multicolumn{2}{|c|}{$\begin{array}{c}\text { Rear-end collisions while turning, } \\
\text { merging, or changing lanes }\end{array}$} & $\begin{array}{c}\text { Rear-end collisions not involving } \\
\text { turning, merging, or changing lanes }\end{array}$ \\
\hline $\begin{array}{l}\text { Signal } \\
\text { Lamp } \\
\text { Color }\end{array}$ & $\begin{array}{c}\text { Struck } \\
\text { (Rear Impact) }\end{array}$ & $\begin{array}{c}\text { Striking } \\
\text { (Front Impact) }\end{array}$ & $\begin{array}{c}\text { Struck } \\
\text { (Rear Impact) }\end{array}$ \\
\hline Amber & 4,975 & & 4,417 & 58,964 \\
\hline Red & 5,115 & 4,172 & 56,771 \\
\hline Total & 10,090 & 8,589 & 115,735 \\
\hline
\end{tabular}




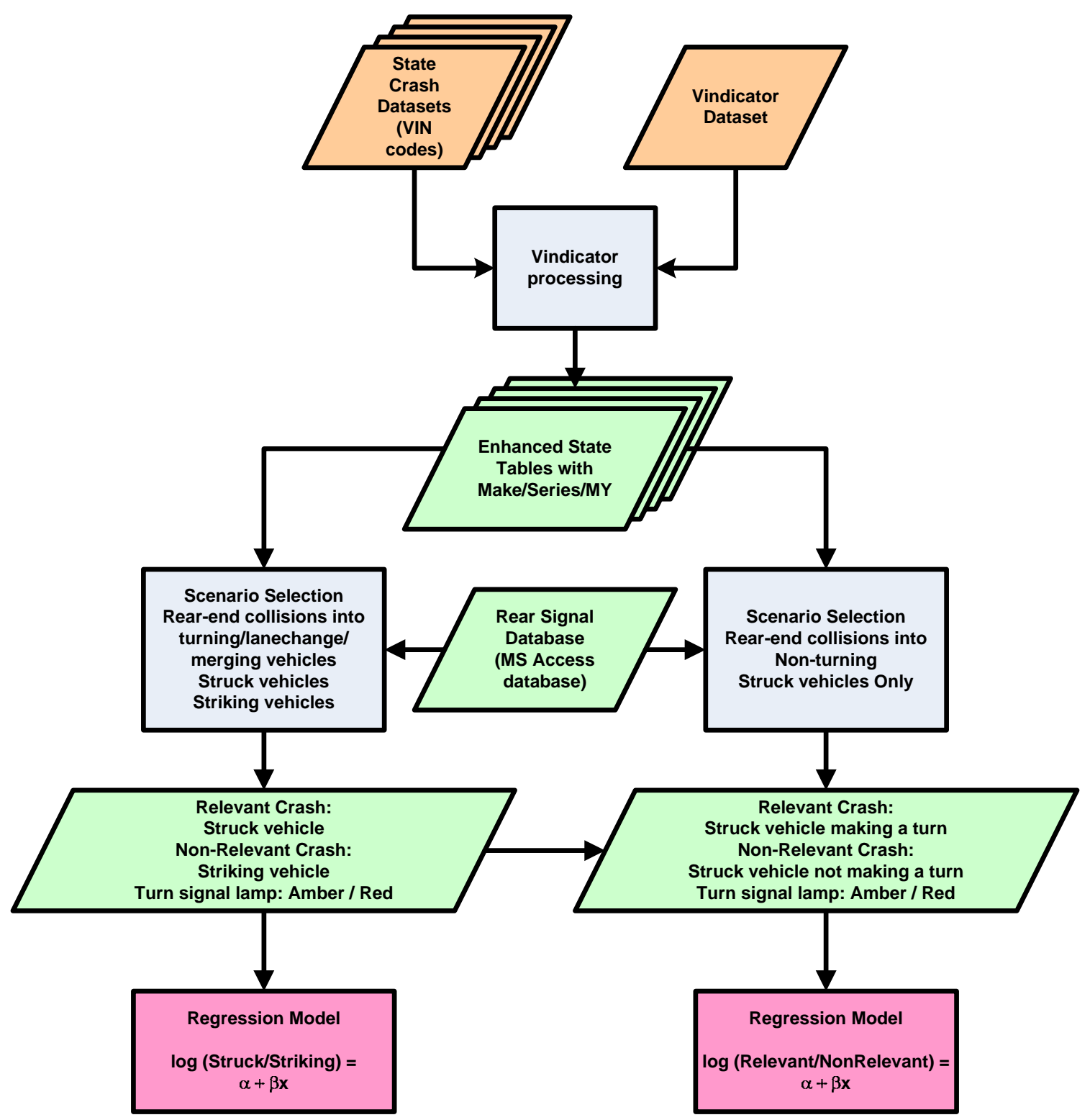

Figure 6. Overview of the data-processing steps that produced the datasets used in the regression analysis. Processes are drawn as rectangles; datasets are drawn as parallelograms. Orange datasets were supplied from external sources; green datasets were generated as part of this project. 


\section{Logistic Regression Models}

Two response variables are defined in separate regression models. The first is the odds of being the struck vehicle versus the striking vehicle in a rear-end collision involving a vehicle turning, merging, or changing lanes (a relevant collision). The second response variable is the odds of being the struck vehicle in a relevant collision (as before) versus a non-relevant collision - a struck vehicle in a rear-end collision involving maneuvers that do not include turning, merging, or changing lanes. For each model, several variables in the datasets were identified as a potential influence on the odds of a crash. Each of these variables was identified and included in a logistic regression in which a stepwise selection procedure was employed which evaluated each variable with respect to its contribution to the predictive power of the model. Each variable was added to the model only if it produced a significantly better predictive model. As variables were added to the model, those already contained in the model were reevaluated and removed if they no longer contributed to the model's predictive power. Table 8 describes individual candidate variables included in the stepwise regression analysis and provides a rationale for their inclusion. Table 9 describes candidate interactions between variables that were also added to the same regression models. Interactions considered in each model included driver age with gender, light condition, and State; light conditions with each of the turn-signal lamp characteristics, and vehicle age with series name.

One reason so many variables were included in this analysis was that, as with any correlational analysis, many variables are likely to be indirectly related to each other. For example, younger drivers are more likely to drive older or less expensive vehicles; older drivers are more likely to drive luxury models. Amber turn signals are always physically separated from red stop lamps, but red turn signals may or may not be separated. In this latter example, to assess the importance of stop and turn signal separation, the model will only evaluate this variable using the red turn signal cases because there are no differences among the amber turn signals. 
Table 8 .

Main effect variables included in the logistic regression model.

\begin{tabular}{|c|c|}
\hline Variable & Description \\
\hline State & This is the State in which the crash occurred. \\
\hline Light Condition & $\begin{array}{l}\text { Because the conspicuity of signal lighting may interact with lighting conditions, } \\
\text { light condition (light, dark) was included in the model. Conditions were } \\
\text { classified as dark if the reported light conditions were "dark" or "dark with } \\
\text { lights." Dawn, dusk, and unknown conditions were excluded from the analysis. }\end{array}$ \\
\hline Gender & Reported gender of the driver. \\
\hline Driver Age Group & $\begin{array}{l}\text { This is a classification of the driver's age as either young ( }<30 \text { years), middle } \\
\text { (30-64 years), and old ( }>64 \text { years). }\end{array}$ \\
\hline Vehicle Age & $\begin{array}{l}\text { This is a continuous variable computed as the calendar year of the crash minus } \\
\text { the model year of the vehicle plus } 1 \text { (to avoid negative numbers from new } \\
\text { vehicles with model numbers greater than the calendar year). Vehicle age at } \\
\text { time of crash has been reported to have an inverse relationship to risk of rear end } \\
\text { collision (e.g., Kahane \& Hertz, 1998). }\end{array}$ \\
\hline Series Name & $\begin{array}{l}\text { This is the model name of the vehicle. It is used to account for factors that may } \\
\text { influence crash risk within select populations of vehicle owners (e.g., Camaro } \\
\text { owners are likely different from Civic owners). }\end{array}$ \\
\hline Body Style & $\begin{array}{l}\text { This variable is correlated with Series Name. It groups vehicles into the } \\
\text { following broad body style categories: Luxury, Sports, Utility, 4-Door, 2-Door, } \\
\text { Passenger Van, and Pickup. It was used as an alternate analysis level. }\end{array}$ \\
\hline Turn Signal Color & $\begin{array}{l}\text { Amber or Red. This is the signal lamp characteristic that identifies the color } \\
\text { of the illuminated turn signal. It is the primary variable of interest in most } \\
\text { prior studies. }\end{array}$ \\
\hline $\begin{array}{l}\text { Turn Signal/Stop Signal } \\
\text { Separation }\end{array}$ & $\begin{array}{l}\text { Yes / No. This variable identifies whether the turn signal shared a compartment } \\
\text { with a brake signal. It is plausible that turn signal color may be less important } \\
\text { than signal separation and only appears to be important because amber turn } \\
\text { signals are by necessity separate from the stop signal. }\end{array}$ \\
\hline $\begin{array}{l}\text { Turn Signal/Tail Lamp } \\
\text { Separation }\end{array}$ & $\begin{array}{l}\text { Yes / No. This variable identifies whether the turn signal shared a compartment } \\
\text { with a tail lamp. The rationale for this variable is similar to the rationale } \\
\text { presented for the preceding variable. }\end{array}$ \\
\hline $\begin{array}{l}\text { Turn Signal Separation from } \\
\text { All }\end{array}$ & $\begin{array}{l}\text { Yes / No. This variable identifies whether a turn signal share any compartments } \\
\text { with other lamps. If either of the two preceding variables is 'yes,' this variable } \\
\text { will be 'yes.' }\end{array}$ \\
\hline Turn Signal Source & $\begin{array}{l}\text { LED / Tungsten. This variable identifies the illumination source of the lamp. } \\
\text { Differences in the rise time of different signal sources could influence the } \\
\text { conspicuity of a signal lamp. }\end{array}$ \\
\hline Turn Signal Optics & $\begin{array}{l}\text { Lens / Reflector. This variable identifies whether the light distribution from a } \\
\text { signal lamp is controlled by a faceted lens, or by a silver reflector. A signal } \\
\text { lamp that employs reflector optics passes light through a smooth lens. }\end{array}$ \\
\hline Turn Signal Lens Color & $\begin{array}{l}\text { Clear / Tinted. This variable identifies whether the turn signal lens is clear or } \\
\text { tinted. In the case of a clear lens, the lamp color is produced by a tinted bulb. In } \\
\text { daylight, the non-energized clear-lens lamp appears silver and can reflect } \\
\text { ambient sunlight. This can reduce the contrast between off and on states. }\end{array}$ \\
\hline
\end{tabular}


Table 9

Interaction terms included in the logistic regression model.

\begin{tabular}{|c|c|c|}
\hline $\begin{array}{l}\text { Interactions } \\
\text { Between }\end{array}$ & Secondary variables & Description \\
\hline \multirow[t]{3}{*}{ Driver Age Group } & Gender & $\begin{array}{l}\text { Young male drivers are often identified as an } \\
\text { especially aggressive group. The rationale for } \\
\text { including this interaction is that crash risk may be } \\
\text { affected by gender differences more among younger } \\
\text { drivers than older drivers. }\end{array}$ \\
\hline & Light Condition & $\begin{array}{l}\text { Crash risk may interact with driver age and light } \\
\text { conditions if, for example, older drivers } \\
\text { disproportionately avoid driving in darkness. }\end{array}$ \\
\hline & State & $\begin{array}{l}\text { Driver age distribution among states may not be } \\
\text { homogeneous. For example, there may be an } \\
\text { observed higher crash risk among older drivers in } \\
\text { Florida than in New Jersey. }\end{array}$ \\
\hline \multirow[t]{7}{*}{ Light Condition } & Turn Signal Color & \multirow{7}{*}{$\begin{array}{l}\text { The rationale for modeling the interaction between } \\
\text { light conditions and each of the lamp characteristics } \\
\text { is that it is plausible that the influence of any lamp } \\
\text { attribute on crash odds could differ under different } \\
\text { ambient light conditions. }\end{array}$} \\
\hline & Turn Signal/Stop Signal Separation & \\
\hline & Turn Signal/Tail Lamp Separation & \\
\hline & Turn Signal Separation from All & \\
\hline & Turn Signal Source & \\
\hline & Turn Signal Optics & \\
\hline & Turn Signal Lens Color & \\
\hline Vehicle Age & Series Name & $\begin{array}{l}\text { The rationale for this interaction is that as a vehicle } \\
\text { ages, changes in vehicle function and ownership } \\
\text { demographics may influence crash odds. }\end{array}$ \\
\hline
\end{tabular}




\section{Results}

\section{Analysis 1: Log Odds of Struck/Striking Role}

The results of each logistic regression will be presented in a tabular form in which the selected effects will be presented along with parameter estimates of each variable. In the interest of clarity, estimates are not reported for variables in which many levels are identified-e.g., vehicle series name (50 levels), vehicle body style ( 8 levels), and State (7 levels). Such variables have been included in this analysis to effectively account for the influence these factors have on the resulting odds ratio so that the effects of interestturn signal lamp characteristics - can be clearly observed. The results of the analysis are shown in Table 10. The part of the regression model related to the lighting configuration fits into the regression as follows:

\begin{tabular}{|c|c|}
\hline Predicted logit of Struck $=$ & Parameter \\
\hline 0.0496 & (Intercept) \\
\hline$+(0.2976)($ FEMALE $)$ & (Gender) \\
\hline$+(.5962)(M I D D L E)$ or $(0.6733)(O L D)$ & (Age) \\
\hline$+(0.1105)(D A R K)$ & (Light Condition) \\
\hline$+(0.0475)($ Middle-aged and Female) or $(-0.3399)($ Old and Female) & (Age x Gender) \\
\hline$+(-0.0434)($ Vehicle Age) & (Vehicle Age) \\
\hline $\begin{array}{l}+(0.3308)(\text { Accord } 4 D) \text { or }(-0.2248)(\text { Altima } 4 D) \text { or } \\
\text { ( } \beta \text { estimate for Series Name)(presence of Series Name) }\end{array}$ & (Series Name) \\
\hline $\begin{array}{l}+(-0.0259)(\text { VehicleAge })(\text { Accord } 4 D) \text { or }(0.0370)(\text { Vehicle Age })(\text { Altima } 4 D) \text { or } \\
(\beta \text { estimate for Series Name x Age interaction)(Vehicle Age)(Series Name) }\end{array}$ & $\begin{array}{l}\text { (Vehicle Age } \mathrm{x} \\
\text { Series Name) }\end{array}$ \\
\hline$+(-0.1786)(A M B E R)$ & (Signal Color) \\
\hline$+(-1.4431)(L E D)$ & (Signal Source) \\
\hline
\end{tabular}

Thus it appears that amber rear turn signals are associated with a smaller odds of a being struck in a rear-end turning crash than red turn signals; likewise it also appears the LED-based turn signals are associated with a even greater reduction in odds of being struck compared with the odds found with tungsten light sources. The 95 percent confidence interval on the odds ratio associated with turn signal color is 0.72 to 0.97 . Reinterpreted as the estimated percent crash reduction effect of amber versus red (reported in previous analyses), this is equivalent to an estimated reduction of between 3 and 28 percent.

The observed effect of turn signal light source is substantially larger than observed for turn signal color. The 95 percent confidence interval on the odds ratio associated with source is 0.083 and 0.673. Interpreted as an estimated percent crash reduction associated with using LED versus tungsten turn signals, this is equivalent to an estimated reduction of between 33 and 92 percent. While the size of the effect appears to be dramatically large, the confidence interval is also wide, suggesting that the result is based on a small portion of the sample data. On further examination of the sample of vehicles contributing to this analysis, it was found that virtually all the samples of LED turn signals were from the 2000-2005 Cadillac DeVille. Essentially, the analysis compared the rear-end collision odds of the 2000-2005 Cadillac DeVille (equipped with LED turn signals) to the same odds for 1991 to 1999 version of the DeVille (equipped with tungsten turn signals). Despite the general trend for older model vehicles to decline 
in their rate of being struck in rear-end collisions, it appears that the newer model DeVilles, equipped with LEDs, buck this trend. Given that the LED effect is based on the implementation in one vehicle model line, it would be inappropriate to generalize this result to all LED turn signal implementations.

Also found was an association between gender and crash odds-female drivers have a greater odds of being struck than male drivers (conversely, male drivers have a greater odds of playing a striking role). Similarly, older and middle aged drivers have greater odds of being struck than younger drivers. There is also an interaction between age and gender-middle-aged female drivers demonstrated an especially greater risk of being struck (or conversely, they demonstrate an especially low risk of striking). 
Table 10

Logistic regression analysis of the odds of struck role in a rear-end collision involving a lead vehicle turning, merging, or changing lanes. Series name and series name by vehicle age interactions were omitted from the table.

\begin{tabular}{|c|c|c|c|c|c|c|}
\hline Predictor & $\beta$ & SE $\beta$ & $\begin{array}{c}\text { Wald's } \\
\chi^{2}\end{array}$ & $d f$ & $p$ & $\begin{array}{c}e^{\beta} \\
\text { Odds } \\
\text { Ratio }\end{array}$ \\
\hline Constant (intercept) & 0.0496 & 0.34 & 0.02 & 1 & 0.88 & 1.05 \\
\hline Gender $($ Male $=0$, Female $=1)$ & 0.2976 & 0.05 & 34.77 & 1 & $<.0001$ & 1.35 \\
\hline \multicolumn{7}{|l|}{ Age Group (Young = 0) } \\
\hline Middle & 0.5962 & 0.05 & 167.77 & 1 & $<.0001$ & 1.82 \\
\hline Old & 0.6733 & 0.08 & 70.90 & 1 & $<.0001$ & 1.96 \\
\hline Light Condition $($ Light $=0$, Dark $=1)$ & 0.1105 & 0.04 & 7.25 & 1 & 0.01 & 1.12 \\
\hline \multicolumn{7}{|l|}{ Gender x Age Group (Young, Male $=0$ ) } \\
\hline Middle, Female & 0.0475 & 0.07 & 0.51 & 1 & 0.48 & 1.05 \\
\hline Old, Female & -0.3399 & 0.12 & 8.13 & 1 & 0.00 & 0.71 \\
\hline Vehicle Age & -0.0435 & 0.05 & 0.83 & 1 & 0.36 & 0.96 \\
\hline \multicolumn{7}{|l|}{ Turn Signals } \\
\hline Color $($ Red $=0$, Amber $=1)$ & -0.1786 & 0.08 & 5.61 & 1 & 0.02 & 0.84 \\
\hline \multirow[t]{2}{*}{ Source $($ Tungsten $=0$, Led $=1)$} & -1.4431 & 0.53 & 7.30 & 1 & 0.01 & 0.24 \\
\hline & & & $\chi^{2}$ & $d f$ & $p$ & \\
\hline \multicolumn{7}{|l|}{ Model evaluation } \\
\hline Likelihood ratio test & & & 792.12 & 117 & $<.0001$ & \\
\hline Score test & & & 778.93 & 117 & $<.0001$ & \\
\hline Wald test & & & 749.78 & 117 & $<.0001$ & \\
\hline \multicolumn{7}{|l|}{ Goodness of fit test } \\
\hline Hosmer and Lemeshow & & & 4.25 & 8 & 0.834 & \\
\hline & & & & & & \\
\hline
\end{tabular}




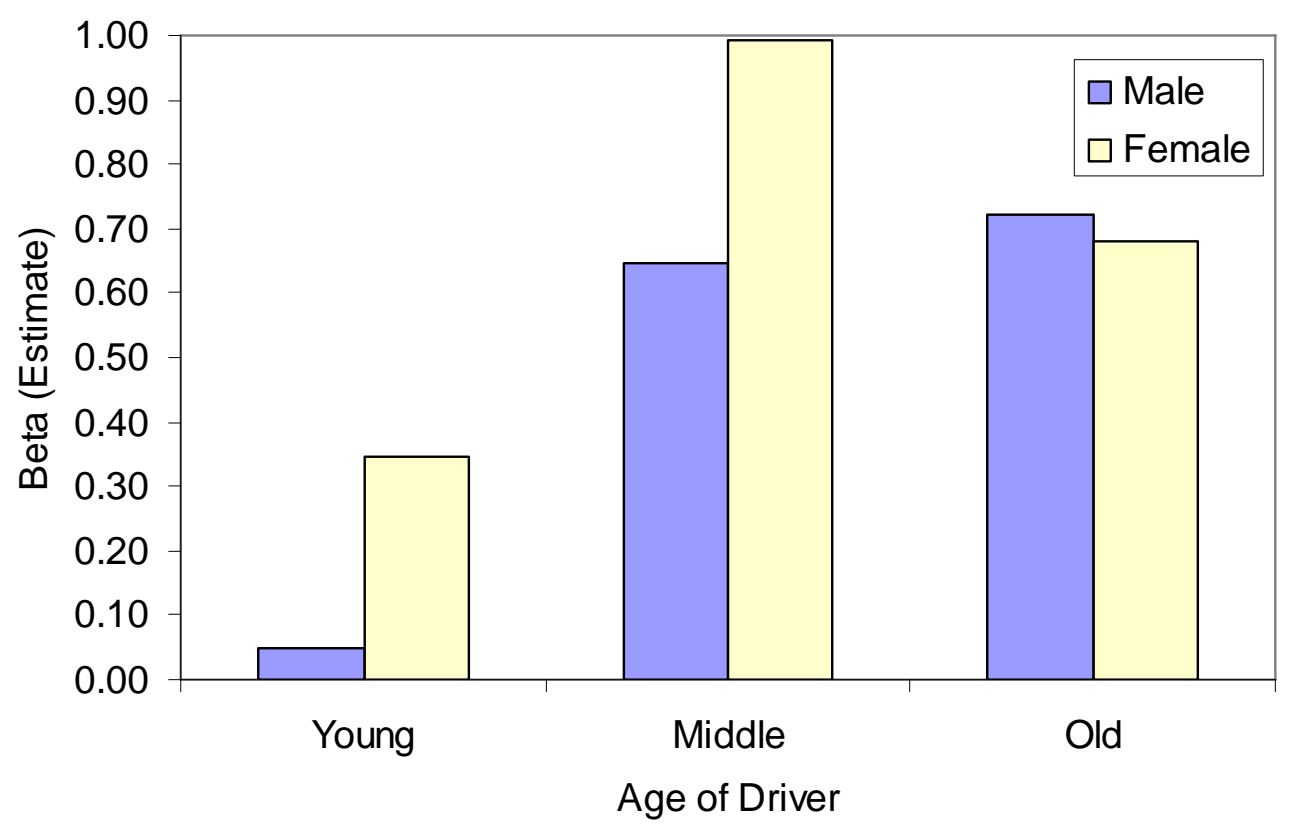

Figure 7. Interaction effect between gender and driver age. The estimate reflects the sum of the estimates for each condition; the larger the estimate, the greater the odds of being the struck driver in a rear-end collision; the lower the estimate, the greater to odds of being the striking driver.

The Influence of Other Turn Signal Characteristics. While an effect of lamp color was observed in the preceding analysis, this does not necessarily preclude the influence of lamp separation on crash odds, although it suggests that lamp color is a better predictor of the observed odds ratio. If lamp color is excluded from the analysis, then separation of the turn signal from the tail lamp becomes a significant predictor, albeit weaker (see Table 11).

The color/separation issue was further explored in a separate analysis of the effect of turn signal separation among vehicles equipped with red turn signals; and in an analysis of the effect of color among vehicles equipped with separated signal lamps. Lamp separation was a poor predictor of crash odds among vehicles equipped with red turn signals (Wald $\chi^{2}=0.93, d f=1, p=.33$ ); and turn-signal color was a poor predictor among vehicles equipped with separated lamps (Wald $\chi^{2}=2.07, d f=1, p=.15$ ). The odds ratio estimates, although unreliable, suggest that color might be more influential on the crash odds than lamp separation - the observed reduction for amber is about 18 percent, for separated lamps it is 11 percent. 
Table 11

Logistic regression analysis of the odds of struck role in a rear-end collision involving a lead vehicle turning, merging, or changing lanes, excluding lamp color as a predictor.

Note that turn signal separation, a factor correlated with lamp color, becomes a predictor of the odds ratio. (As in Table 10, series name and series name by vehicle age interactions are omitted from this table).

\begin{tabular}{|c|c|c|c|c|c|c|}
\hline Predictor & $\beta$ & SE $\beta$ & $\begin{array}{c}\text { Wald's } \\
\chi^{2}\end{array}$ & $d f$ & $p$ & $\begin{array}{c}e^{\beta} \\
\text { Odds } \\
\text { Ratio }\end{array}$ \\
\hline Constant (intercept) & 0.0696 & 0.34 & 0.04 & 1 & 0.84 & 1.07 \\
\hline Gender $($ Male $=0$, Female $=1)$ & 0.2980 & 0.05 & 34.85 & 1 & $<.0001$ & 1.35 \\
\hline \multicolumn{7}{|l|}{ Age Group (Young = 0) } \\
\hline Middle & 0.5951 & 0.05 & 167.24 & 1 & $<.0001$ & 1.81 \\
\hline Old & 0.6733 & 0.08 & 70.90 & 1 & $<.0001$ & 1.96 \\
\hline Light Condition $($ Light $=0$, Dark $=1)$ & 0.1107 & 0.04 & 7.28 & 1 & 0.01 & 1.12 \\
\hline \multicolumn{7}{|l|}{ Gender $\mathrm{x}$ Age Group (Young, Male $=0$ ) } \\
\hline Middle, Female & 0.0491 & 0.07 & 0.54 & 1 & 0.46 & 1.05 \\
\hline Old, Female & -0.3402 & 0.12 & 8.14 & 1 & 0.00 & 0.71 \\
\hline Vehicle Age & -0.0479 & 0.05 & 1.06 & 1 & 0.32 & 0.95 \\
\hline \multicolumn{7}{|l|}{ Turn Signals Separation } \\
\hline Tail Lamp (No $=0$, Yes $=1)$ & -0.1480 & 0.08 & 3.89 & 1 & 0.05 & 0.86 \\
\hline \multirow[t]{2}{*}{ Source $($ Tungsten $=0$, Led $=1)$} & -1.4431 & 0.53 & 7.30 & 1 & 0.01 & 0.24 \\
\hline & & & $\chi^{2}$ & $d f$ & $p$ & \\
\hline \multicolumn{7}{|l|}{ Model evaluation } \\
\hline Likelihood ratio test & & & 790.41 & 117 & $<.0001$ & \\
\hline Score test & & & 777.20 & 117 & $<.0001$ & \\
\hline Wald test & & & 748.04 & 117 & $<.0001$ & \\
\hline \multicolumn{7}{|l|}{ Goodness of fit test } \\
\hline Hosmer and Lemeshow & & & 3.76 & 8 & 0.878 & \\
\hline & & & & & & \\
\hline
\end{tabular}

Table 12

Cases identifying turn signal separation from stop lamp and tail lamps. Note that combined signals are not possible with amber turn signals.

\begin{tabular}{|l|r|r|r|r|r|r|r|}
\hline & & \multicolumn{2}{|c|}{$\begin{array}{c}\text { Tail Separate } \\
\text { From Turn Signal }\end{array}$} & \multicolumn{2}{|c|}{$\begin{array}{c}\text { Stop Lamp Separate } \\
\text { From Turn Signal }\end{array}$} \\
\hline & & & Yes & No & Yes & No \\
\hline \multirow{2}{*}{ Lamp Color } & Amber & & 9,392 & 0 & 9,392 & 0 \\
\cline { 2 - 8 } & Red & & 2,389 & 6,898 & 2,633 & 6,654 \\
\hline
\end{tabular}




\section{Analysis 2: Log Odds of Relevant/Non-Relevant Collisions}

In this model, instead of employing striking vehicles as the contrast group to computing odds, vehicles struck in non-turning (non-relevant) collisions were employed. That is, the odds are the number of vehicles stuck while attempting to turn, merge, or change lanes (a relevant crash) divided by the number vehicles involved in non-relevant collisions. As mentioned earlier, this duplicates the analysis approach taken in previously published reports. For this measure, no relationship between the odds of a relevant crash and turn signal color or source was found. Perhaps turn-signal color and source influence many kinds of rear-end collision types - both relevant and non-relevant crashes alikeeffectively obscuring the influence. Indeed, in the case of the 2000-2005 Cadillac DeVille, both the brake lamp and turn-signal sources are LEDs. It is probable that on any given vehicle, the characteristics of a rear turn-signal are related to the characteristics of other rear signals. Use of the relevant/non-relevant odds ratio seems to assume the effect of turn signal is independent of the effect of brake signal. Consequently, the remaining analyses in this report will resume use of the logit of the odds of playing the struck role in a relevant rear-end collision as the response variable for each model.

The odds of a relevant crash were associated with turn signal optics. Vehicles with reflector optics appear less likely to be involved in relevant collisions with lens optics. This translates to an approximately 32-percent reduction in the odds of involvement in relevant crashes with reflector optics compared to lens optics $(95 \% \mathrm{CI}=5$ to $51 \%$ ). It is unclear why this happens, although the sample of vehicles equipped with reflector optics is small ( $0.8 \%$ of the sample) and seems to be dominated by late-model (1999-2004) Ford Mustangs, driven by young drivers (58\% - 18\% female, 40\% male). As discussed earlier with respect to the LED finding in the first analysis, it seems inappropriate to generalize this particular result to all rear turn signals equipped with reflector optics.

The difference between this analysis and the first one suggests that selection of a contrast group can influence the observed effects. In this case, an influence of turn signal color is present in the first analysis and absent in the second. One reason for its absence in the second analysis might be that both the crash-relevant group (rear-end collisions into vehicles making turn-signal-relevant maneuvers) and the contrast group (rear-end collisions into vehicles not making turn-signal relevant maneuvers) are similarly affected by the rear turn signal configuration. Rear signals are visible for both crash groups, and this allows the possibility that rear signal characteristics might both enhance turn-signal conspicuity as well as stop-lamp conspicuity. Thus, if both the relevant crash group and the contrast group are similarly affected by rear signal characteristics, no effect would be observed in the logistic regression. On the other hand, the first analysis using the striking driver's vehicle as a contrast group seems to remove the possibility that the striking crash could be influenced by the rear signals - they are completely out of the striking driver's direct sight. Consequently, the first analysis is preferred to the second analysis. 
Table 13.

Logistic regression analysis of the odds that a vehicle is making a tuning, merging, or lane change maneuver in a rear-end collision. Series name effects (50 total) were omitted from the table.

\begin{tabular}{|c|c|c|c|c|c|c|}
\hline Predictor & $\beta$ & SE $\beta$ & $\begin{array}{c}\text { Wald's } \\
\chi^{2}\end{array}$ & $d f$ & $p$ & $\begin{array}{c}e^{\beta} \\
\text { Odds } \\
\text { Ratio }\end{array}$ \\
\hline Constant (intercept) & -2.9646 & 0.102 & 847.99 & 1 & $<.0001$ & 0.052 \\
\hline \multicolumn{7}{|l|}{ State $(\mathrm{PA}=1)$} \\
\hline Florida & 0.1447 & 0.078 & 3.41 & 1 & 0.065 & 1.156 \\
\hline Kentucky & 0.1856 & 0.066 & 7.95 & 1 & 0.005 & 1.204 \\
\hline Maryland & 0.1288 & 0.072 & 3.23 & 1 & 0.072 & 1.137 \\
\hline Michigan & 0.2019 & 0.061 & 10.95 & 1 & 0.001 & 1.224 \\
\hline North Carolina & 0.336 & 0.058 & 33.43 & 1 & $<.0001$ & 1.399 \\
\hline New Jersey & 0.5947 & 0.058 & 107.13 & 1 & $<.0001$ & 1.812 \\
\hline Gender $($ Male $=0$, Female $=1)$ & 0.1338 & 0.022 & 34.45 & 1 & $<.0001$ & 1.143 \\
\hline \multicolumn{7}{|l|}{ Age Group (Young $=0$ ) } \\
\hline Middle & -0.0406 & 0.025 & 2.71 & 1 & 0.0998 & 0.96 \\
\hline Old & 0.2129 & 0.043 & 24.75 & 1 & $<.0001$ & 1.237 \\
\hline Vehicle Age & 0.0335 & 0.004 & 94.32 & 1 & $<.0001$ & 1.034 \\
\hline \multicolumn{7}{|l|}{ Turn Signals } \\
\hline \multirow[t]{2}{*}{ Optics $($ Lens $=0$, Reflector $=1)$} & -0.3868 & 0.17 & 5.13 & 1 & 0.024 & 0.679 \\
\hline & & & $\chi^{2}$ & $d f$ & $p$ & \\
\hline \multicolumn{7}{|l|}{ Model evaluation } \\
\hline Likelihood ratio test & & & 639.86 & 65 & $<.0001$ & \\
\hline Score test & & & 641.90 & 65 & $<.0001$ & \\
\hline Wald test & & & 634.22 & 65 & $<.0001$ & \\
\hline \multicolumn{7}{|l|}{ Goodness of fit test } \\
\hline Hosmer and Lemeshow & & & 13.73 & 8 & 0.089 & \\
\hline & & & & & & \\
\hline
\end{tabular}


Analysis 3: Vehicles grouped by body style

In this analysis, vehicle body style was substituted for vehicle series name using VINDICATOR's vehicle body style field. The grouping generally collected together similar vehicles (e.g., passenger vans: Dodge Caravan and Ford Windstar; utility vehicles: Ford Explorer, Jeep Grand Cherokee, Chevy Blazer), although the 2- and 4door vehicle categories did not distinguish differences in vehicle size (e.g., a Ford Escort and Pontiac Grand Am were classified together as 2-door vehicles). Vehicle groupings are shown in Table 14 along with turn signal color breakdowns.

The analysis (shown in Table 15) suggests that the 4-door vehicles and passenger vans are not particularly different from the 2-door comparison group with respect to the odds of being the struck vehicle in relevant rear-end collisions. Luxury vehicles appear to be more likely to play the struck role; while pickup trucks, sports cars, and utility vehicles are less likely to be the struck vehicle.

The pattern of association between the rear turn-signal characteristics and the odds of being struck in relevant rear-end collisions is similar to the pattern reported for Model 1. That is, there is an effect of lamp color such that amber turn signals appear to be associated with reduced odds of rear-end collision. The 95-percent confidence interval on the odds ratio associated with turn signal color is 0.87 to $0.99-\mathrm{a}$ weaker influence than previously seen. The equivalent percent crash reduction associated with amber lamps would be between 1 and 13 percent.

The observed effect of turn signal light source is, like before, larger than turn signal color. The 95-percent confidence interval on the odds ratio associated with LED (versus tungsten) light sources is 0.25 to 0.81 . Interpreted as an estimated percent crash reduction associated with LED turn signal sources, this would be equivalent to an estimated reduction of between 19 to 75 percent.

Overall, the body style variable produced a less powerful model (indicated by the higher goodness-of-fit score $\chi^{2}$ in the Hosmer and Lemeshow test), and possibly absorbed some of the predictive power formerly attributed to turn signal characteristics. 
Table 14

Breakdown of the vehicle sample by body style and turn signal color.

\begin{tabular}{|c|c|c|c|c|}
\hline \multirow{2}{*}{ Body style } & \multirow[b]{2}{*}{ Series Name } & \multicolumn{2}{|c|}{ Turn Signal Color } & \multirow[b]{2}{*}{ Total } \\
\hline & & Amber & Red & \\
\hline \multirow[t]{7}{*}{ 2-Door } & ACCORD 2D & 93 & 127 & 220 \\
\hline & CAVALIER 2D & & 369 & 369 \\
\hline & CIVIC 2D COUPE & 295 & 120 & 415 \\
\hline & ECLIPSE 2D 2WD & & 171 & 171 \\
\hline & ESCORT 2D & 69 & 108 & 177 \\
\hline & GRAND AM 2D & 40 & 105 & 145 \\
\hline & THUNDERBIRD 2D & & 136 & 136 \\
\hline \multicolumn{2}{|l|}{ 2-Door Total } & 497 & 1,136 & 1,633 \\
\hline \multirow[t]{30}{*}{ 4-Door } & 626 SEDAN & 265 & & 265 \\
\hline & 810/MAXIMA SEDAN & 356 & 5 & 361 \\
\hline & ACCORD 4D & 1,308 & & 1,308 \\
\hline & ALTIMA 4D & 444 & 102 & 546 \\
\hline & CAMRY 4D 2WD & 997 & & 997 \\
\hline & CAVALIER 4D & & 372 & 372 \\
\hline & CENTURY 4D & & 325 & 325 \\
\hline & CIERA 4D & & 127 & 127 \\
\hline & CIVIC 4D & 350 & 155 & 505 \\
\hline & CONTOUR 4D & & 238 & 238 \\
\hline & COROLLA SEDAN 2WD & 727 & & 727 \\
\hline & ELANTRA 4D & 164 & & 164 \\
\hline & ESCORT 4D & 103 & 224 & 327 \\
\hline & FOCUS 4D & & 252 & 252 \\
\hline & GALANT 4D 2WD & 82 & 146 & 228 \\
\hline & GRAND AM 4D & 83 & 325 & 408 \\
\hline & GRAND PRIX 4D & 64 & 182 & 246 \\
\hline & INTREPID 4D & 133 & 136 & 269 \\
\hline & JETTA SEDAN & 130 & & 130 \\
\hline & LESABRE 4D & & 258 & 258 \\
\hline & LTD/CROWN VICTORIA 4D & 97 & 161 & 258 \\
\hline & LUMINA 4D & & 331 & 331 \\
\hline & MALIBU 4D & 295 & 4 & 299 \\
\hline & MARQUIS/G. MARQ. 4D & & 185 & 185 \\
\hline & NEON 4D & & 316 & 316 \\
\hline & SABLE 4D & 4 & 291 & 295 \\
\hline & SENTRA 4D & 374 & 3 & 377 \\
\hline & SL 4D & 446 & & 446 \\
\hline & STRATUS 4D & 132 & 81 & 213 \\
\hline & TAURUS 4D & 131 & 783 & 914 \\
\hline \multicolumn{2}{|l|}{ 4-Door Total } & 6,685 & 5,002 & 11,687 \\
\hline
\end{tabular}


Table 14. (continued)

Breakdown of the vehicle sample by body style and turn signal color.

\begin{tabular}{|c|c|c|c|c|}
\hline \multirow{2}{*}{ Body Style } & \multirow[b]{2}{*}{ Series Name } & \multicolumn{2}{|c|}{ Turn Signal Color } & \multirow[b]{2}{*}{ Total } \\
\hline & & Amber & Red & \\
\hline \multirow[t]{2}{*}{ LUXURY } & DEVILLE 4D FWD & & 237 & 237 \\
\hline & TOWN CAR/CONT. 4D & & 203 & 203 \\
\hline \multicolumn{2}{|l|}{ LUXURY Total } & & 440 & 440 \\
\hline \multirow[t]{3}{*}{ PASSENGER VAN } & CARAVAN VAN 2WD & & 322 & 322 \\
\hline & GRAND CARAVAN 2WD & & 397 & 397 \\
\hline & WINDSTAR VAN & 351 & & 351 \\
\hline \multicolumn{2}{|c|}{ PASSENGER VAN Total } & 351 & 719 & 1,070 \\
\hline \multirow[t]{6}{*}{ PICKUP } & 10/1500 PU $1 / 2 \mathrm{~T}$ & 2 & 127 & 129 \\
\hline & F150 PICKUP 4X2 & & 252 & 252 \\
\hline & F150 SUPER PU 4X2 & & 52 & 52 \\
\hline & RANGER PICKUP 4X2 & 233 & 77 & 310 \\
\hline & RANGER SUPER PU 4X2 & 146 & 70 & 216 \\
\hline & S10 PICKUP 4X2 & & 290 & 290 \\
\hline \multicolumn{2}{|l|}{ PICKUP Total } & 381 & 868 & 1,249 \\
\hline \multirow[t]{2}{*}{ SPORTS } & CAMARO 2D & & 97 & 97 \\
\hline & MUSTANG 2D & 84 & 264 & 348 \\
\hline \multicolumn{2}{|l|}{ SPORTS Total } & 84 & 361 & 445 \\
\hline \multirow[t]{5}{*}{ UTILITY } & CHEROKEE 4D 4X4 & 332 & & 332 \\
\hline & EXPLORER 4D 4X2 & 92 & 70 & 162 \\
\hline & EXPLORER 4D 4X4 & 328 & 306 & 634 \\
\hline & GRAND CHEROKEE 4D 4X4 & 642 & & 642 \\
\hline & T10 BLAZER 4D 4X4 & & 368 & 368 \\
\hline \multicolumn{2}{|l|}{ UTILITY Total } & 1,394 & 744 & 2,138 \\
\hline \multicolumn{2}{|l|}{ Grand Total } & 9,392 & 9,287 & 18,662 \\
\hline
\end{tabular}


Table 15

Logistic regression analysis of the odds of struck role in a rear-end collision involving a lead vehicle turning, merging, or changing lanes.

\begin{tabular}{|c|c|c|c|c|c|c|}
\hline Predictor & $\beta$ & SE $\beta$ & $\begin{array}{c}\text { Wald's } \\
\chi^{2}\end{array}$ & $d f$ & $p$ & $\begin{array}{c}e^{\beta} \\
\text { Odds } \\
\text { Ratio }\end{array}$ \\
\hline Constant (intercept) & -0.0702 & 0.068 & 1.08 & 1 & 0.30 & 0.93 \\
\hline Gender $($ Male $=0$, Female $=1)$ & 0.3074 & 0.05 & 38.02 & 1 & $<.0001$ & 1.36 \\
\hline \multicolumn{7}{|l|}{ Age Group (Young = 0) } \\
\hline Middle & 0.5781 & 0.05 & 164.50 & 1 & $<.0001$ & 1.78 \\
\hline Old & 0.6544 & 0.08 & 71.87 & 1 & $<.0001$ & 1.92 \\
\hline Light Condition $($ Light $=0$, Dark $=1)$ & 0.1059 & 0.04 & 6.78 & 1 & 0.009 & 1.11 \\
\hline \multicolumn{7}{|l|}{ Gender x Age Group (Young, Male $=0$ ) } \\
\hline Middle, Female & 0.06 & 0.07 & 0.82 & 1 & 0.364 & 1.06 \\
\hline Old, Female & -0.3305 & 0.12 & 7.83 & 1 & 0.005 & 0.72 \\
\hline Vehicle Age & -0.0289 & 0.004 & 39.87 & 1 & $<0.0001$ & 0.97 \\
\hline \multicolumn{7}{|l|}{ Vehicle Body style (2-Door $=0$ ) } \\
\hline 4-Door & -0.0194 & 0.058 & 0.1133 & 1 & 0.7365 & 0.981 \\
\hline Luxury & 0.3803 & 0.126 & 9.0717 & 1 & 0.0026 & 1.463 \\
\hline Passenger Van & -0.0436 & 0.086 & 0.2593 & 1 & 0.6106 & 0.957 \\
\hline Pickup & -0.2629 & 0.081 & 10.4646 & 1 & 0.0012 & 0.769 \\
\hline Sports (versus 2-Door) & -0.2701 & 0.115 & 5.5095 & 1 & 0.0189 & 0.763 \\
\hline Utility (versus 2-Door) & -0.1968 & 0.071 & 7.5903 & 1 & 0.0059 & 0.821 \\
\hline \multicolumn{7}{|l|}{ Turn Signals } \\
\hline Color $(\operatorname{Red}=0$, Amber $=1)$ & -0.0734 & 0.033 & 5.0078 & 1 & 0.0252 & 0.929 \\
\hline \multirow[t]{3}{*}{ Source $($ Tungsten $=0$, Led $=1)$} & -0.7979 & 0.302 & 6.9642 & 1 & 0.0083 & 0.45 \\
\hline & & & & & & \\
\hline & & & $\chi^{2}$ & $d f$ & $p$ & \\
\hline \multicolumn{7}{|l|}{ Model evaluation } \\
\hline Likelihood ratio test & & & 604.430 & 15 & $<.0001$ & \\
\hline Score test & & & 597.663 & 15 & $<.0001$ & \\
\hline Wald test & & & 581.789 & 15 & $<.0001$ & \\
\hline \multicolumn{7}{|l|}{ Goodness of fit test } \\
\hline Hosmer and Lemeshow & & & 7.359 & 8 & 0.4984 & \\
\hline & & & & & & \\
\hline
\end{tabular}




\section{Analysis 4: Turn-signal color changes within models}

This analysis included vehicle models in which amber and red turn signals appeared on the same model in different model years spanning 1990 to 2005 . Models that have had exclusively amber turn signals or exclusively red turn signals throughout their model history were excluded from this analysis. For example, in 1996, the styling on the Ford Taurus was redesigned to use amber turn signals in anticipation of marketing the vehicle to European customers. The styling was given a minor revision in 1998 - the amber lens was replaced by a red lens. The next major styling change occurred in the 2000 model year. This evolution is shown in Figure 8. An analysis of within-model signal lamp change may help control factors related to driver demographics that may differ between models. That is, there are likely to be greater similarities between two drivers of the same vehicle model with differently colored turn signals, than there are between two drivers of different models with differently colored turn signals. Use of the series name variable helps account for such differences, allowing the variables associated with lamp characteristics to shine through.

As before, the results suggest that the odds of being the struck vehicle in a relevant rear-end collision are smaller with amber turn signals than with red turn signals. The odds ratio of amber versus red turn signals is 0.785. Reinterpreting this effect estimate as a percent crash reduction, the use of amber turn signals may reduce the risk of rear end collision by about 22 percent. A 95-percent confidence interval places the lower and upper bound of this estimate between 12 and 30 percent. Driver age and gender were also strongly associated with the odds of being struck. The odds ratio of female to male drivers was 1.35; the odds ratio of middle to younger-aged drivers is 1.83 , and older to younger-aged drivers is 1.84. Finally, a relationship was also observed between the vehicle series name and the odds of being struck, suggesting that vehicle series contributed some predictive power to the model. 

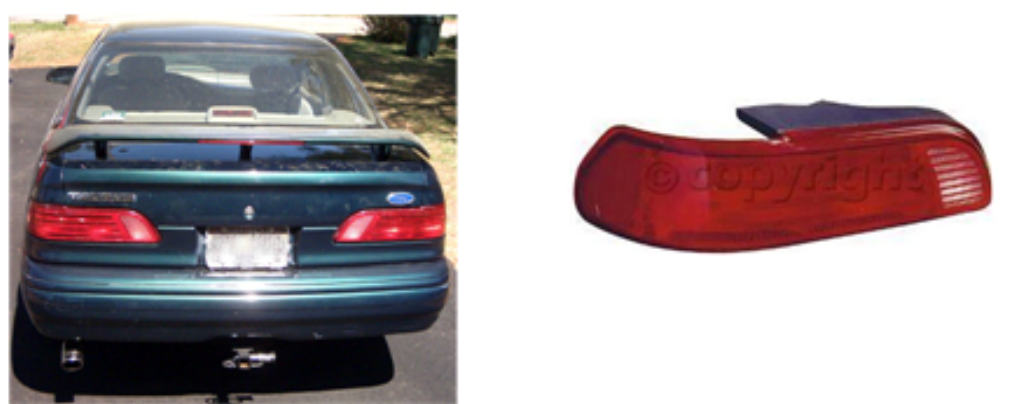

1990-1995
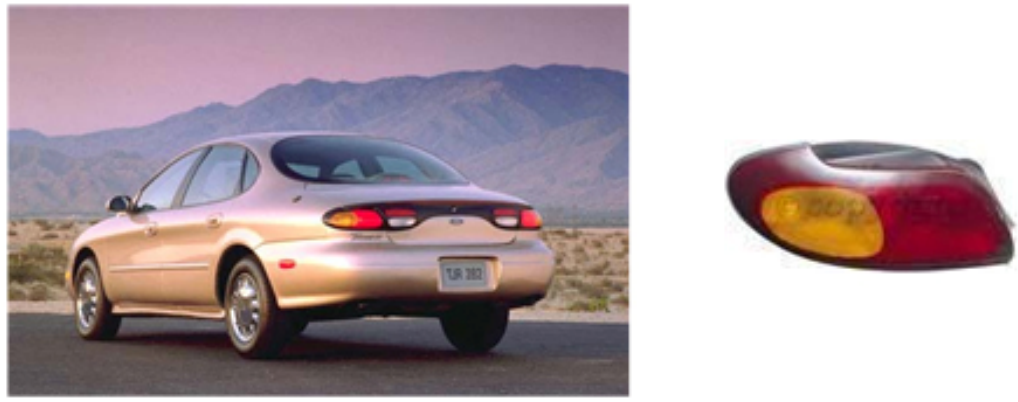

1996-1997
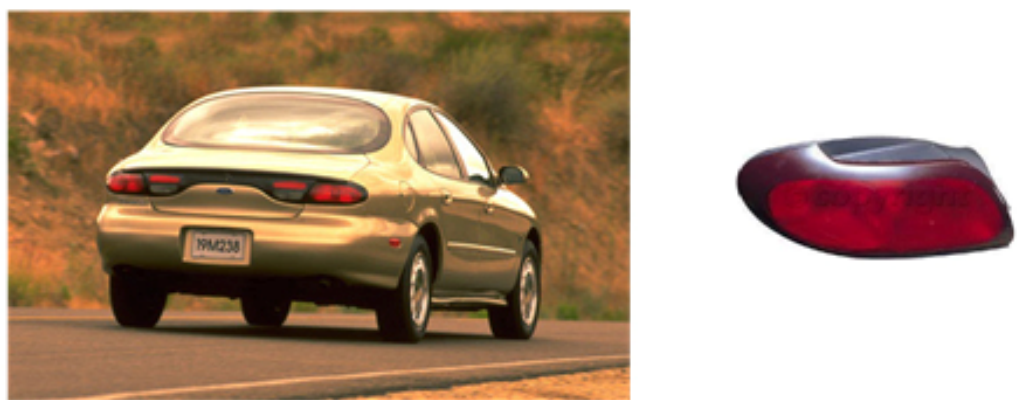

1998-1999
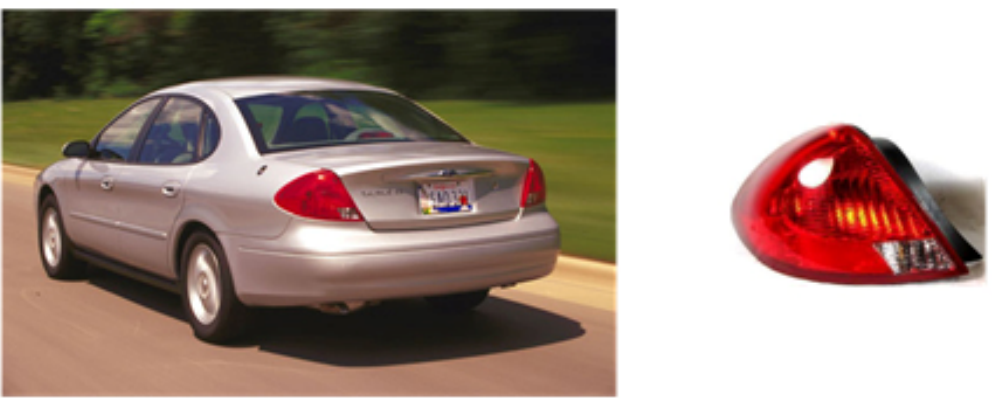

2000-2003

Figure 8. Changes in turn signal color within the Ford Taurus from 1990 to 2003. 
Table 16.

Logistic regression analysis of the odds of struck role in a rear-end collision involving a lead vehicle turning, merging, or changing lanes examining only vehicle models in which the turn signal color was changed within the model's lifespan.

\begin{tabular}{|c|c|c|c|c|c|c|}
\hline Predictor & $\beta$ & SE $\beta$ & $\begin{array}{c}\text { Wald's } \\
\chi^{2}\end{array}$ & $D f$ & $p$ & $\begin{array}{c}e^{\beta} \\
\text { Odds } \\
\text { Ratio }\end{array}$ \\
\hline Constant (intercept) & -0.2058 & 0.123 & 2.802 & 1 & 0.094 & 0.814 \\
\hline Gender $($ Male $=0$, Female $=1)$ & 0.2968 & 0.050 & 35.791 & 1 & $<.0001$ & 1.350 \\
\hline \multicolumn{7}{|l|}{ Age Group (Young = 0) } \\
\hline Middle & 0.6042 & 0.051 & 140.037 & 1 & $<.0001$ & 1.830 \\
\hline Old & 0.6111 & 0.102 & 36.080 & 1 & $<.0001$ & 1.842 \\
\hline \multicolumn{7}{|l|}{ Vehicle Series (Escort 4D =0) } \\
\hline 10/1500 PU 1/2T & -0.3948 & 0.221 & 3.1944 & 1 & 0.0739 & 0.674 \\
\hline 810/MAXIMA SEDAN & 0.0107 & 0.166 & 0.0042 & 1 & 0.9484 & 1.011 \\
\hline ACCORD 2D & 0.1836 & 0.186 & 0.9747 & 1 & 0.3235 & 1.202 \\
\hline ALTIMA 4D & 0.0729 & 0.151 & 0.235 & 1 & 0.6279 & 1.076 \\
\hline CIVIC 2D COUPE & 0.1474 & 0.159 & 0.856 & 1 & 0.3548 & 1.159 \\
\hline CIVIC 4D & 0.3636 & 0.153 & 5.6567 & 1 & 0.0174 & 1.439 \\
\hline ESCORT 2D & -0.0767 & 0.195 & 0.1551 & 1 & 0.6937 & 0.926 \\
\hline EXPLORER 4D 4X2 & -0.0673 & 0.203 & 0.1102 & 1 & 0.7399 & 0.935 \\
\hline EXPLORER 4D 4X4 & -0.4114 & 0.145 & 8.0957 & 1 & 0.0044 & 0.663 \\
\hline GALANT 4D 2WD & 0.1635 & 0.185 & 0.7843 & 1 & 0.3758 & 1.178 \\
\hline GRAND AM 2D & -0.0957 & 0.210 & 0.2081 & 1 & 0.6483 & 0.909 \\
\hline GRAND AM 4D & 0.0040 & 0.157 & 0.0007 & 1 & 0.9795 & 1.004 \\
\hline GRAND PRIX 4D & -0.1015 & 0.178 & 0.3244 & 1 & 0.5689 & 0.904 \\
\hline INTREPID 4D & -0.062 & 0.175 & 0.1259 & 1 & 0.7228 & 0.94 \\
\hline LTD/CROWN VICTORIA 4D & -0.336 & 0.178 & 3.5507 & 1 & 0.0595 & 0.715 \\
\hline MALIBU 4D & 0.3181 & 0.175 & 3.2936 & 1 & 0.0695 & 1.375 \\
\hline MUSTANG 2D & -0.3669 & 0.165 & 4.9639 & 1 & 0.0259 & 0.693 \\
\hline RANGER PICKUP 4X2 & -0.2173 & 0.171 & 1.6231 & 1 & 0.2027 & 0.805 \\
\hline RANGER SUPER PU 4X2 & 0.1513 & 0.187 & 0.6526 & 1 & 0.4192 & 1.163 \\
\hline SABLE 4D & 0.0379 & 0.172 & 0.0486 & 1 & 0.8256 & 1.039 \\
\hline SENTRA 4D & 0.138 & 0.165 & 0.6961 & 1 & 0.4041 & 1.148 \\
\hline STRATUS 4D & 0.0079 & 0.189 & 0.0017 & 1 & 0.9668 & 1.008 \\
\hline TAURUS 4D & 0.032 & 0.137 & 0.0548 & 1 & 0.8149 & 1.032 \\
\hline \multicolumn{7}{|l|}{ Turn Signals } \\
\hline \multirow[t]{2}{*}{ Color $(\operatorname{Red}=0$, Amber $=1)$} & -0.2425 & 0.059 & 16.961 & 1 & $<.0001$ & 0.785 \\
\hline & & & $\chi^{2}$ & $D f$ & $p$ & \\
\hline \multicolumn{7}{|l|}{ Model evaluation } \\
\hline Likelihood ratio test & & & 290.278 & 27 & $<.0001$ & \\
\hline Score test & & & 286.235 & 27 & $<.0001$ & \\
\hline Wald test & & & 277.546 & 27 & $<.0001$ & \\
\hline \multicolumn{7}{|l|}{ Goodness of fit test } \\
\hline Hosmer and Lemeshow & & & 9.9706 & 8 & 0.2671 & \\
\hline & & & & & & \\
\hline
\end{tabular}




\section{Conclusions}

With any regression analysis, one should remember that merely finding a relationship between a variable and a response measure does not demonstrate that the variable caused the response. In the preceding analysis, a relationship seems to exist between turn signal color and the odds of involvement as the struck vehicle in rear-end collisions. Changing the color of a turn signal from red to amber appears to reduce the odds of being struck by 3 to 28 percent. The exact mechanism responsible for this, however, is unclear.

Although rear turn-signal color is implicated, it is important to recognize that signal color is also confounded with other factors that may contribute to this relationship. For example, if signal lamp color is dropped from the regression model, turn-signal/taillamp separation becomes a predictor, albeit weaker. It is also important to recognize that the lamp characteristics included in the logistic regressions are incomplete. It is plausible that characteristics of the light output of amber and red signal lamps differ in systematic ways. Perhaps an amber turn signal appears brighter than a red one. Although prior evidence (Mortimer \& Sturgis, 1974) suggests that a red lamp is more conspicuous than an amber one, this evidence was collected under static viewing conditions that are quite different from the conditions drivers typically face on a roadway where the signal lamps are likely first detected in the peripheral visual field. Does a red lamp still look more conspicuous than an amber lamp when offset 10 degrees from the direction of gaze? If this is true, then the differences observed between red and amber may not be so much related to differences in color as it is to differences in lamp brightness.

The results also show that the choice of comparative data can also influence the observed results. Using lead vehicles involved in non-relevant rear-end collisions (with respect to turn-signal operations) as comparative data, Analysis 2 did not find any relationship between color and the odds of involvement in a relevant crash. This suggests that the non-relevant crash data may have not been as non-relevant as previous researchers believed. Whatever influences a specific turn signal characteristic may have had on a driver's ability to detect and react to a turning or merging lead vehicle, that same characteristic could have also influenced the detectability of other (perhaps non-relevant) maneuvers of a lead vehicle. This influence crosstalk between the target and reference datasets could diminish the chance of observing an influence of a rear signal characteristic on the odds of a particular crash. Instead, the reference group should share as many similarities as possible with the target group except that the variables of specific interest - the rear signal lamp characteristics - should play no conceivable role in the reference group crashes. 


\section{References}

Kahane, C. J., \& Hertz, E. (1998). The long-term effectiveness of Center High Mounted Stop Lamps in passenger cars and light trucks (Technical Report No. DOT HS 808 696). Washington, DC: National Highway Traffic Safety Administration.

Luoma, J., Flannagan, M. J., Sivak, M., Aoki, M., \& Traube, E. C. (1995). Effects of turn-signal color on reaction times to brake signals (Technical Report No. UMTRI-95-5). Ann Arbor, MI: The University of Michigan Transportation Research Institute.

Luoma, J., Sivak, M., \& Flannagan, M. J. (2006). Effects of dedicated stop lamps on nighttime rear-end collisions (Technical Report No. UMTRI-2006-15). Ann Arbor, MI: University of Michigan Transportation Research Institute.

Maurer, P. W. (1980). History of automotive lighting in Europe (Technical Paper No. 800339). Warrendale, PA: Society of Automotive Engineers.

Moore, D. W., \& Rumar, K. (1999). Historical development and current effectiveness of rear lighting systems (Technical Report No. UMTRI-99-31). Ann Arbor, MI: University of Michigan Transportation Research Institute.

Mortimer, R. G., \& Sturgis, S. P. (1974). Evaluations of automotive rear lighting and signaling systems in driving simulator and road tests (Final Report No. UMHSRI-HF-74-24). Washington, DC: National Highway Traffic Safety Administration.

Post, D. V. (1975). Performance requirements for turn and hazard warning signals (Final Report No. UM-HSRI-HF-75-5/DOT-HS-4-01001). Washington, DC: National Highway Traffic Safety Administration.

Sivak, M., Flannagan, M. J., Miyokawa, T., \& Traube, E. C. (2000). Color identification in the visual periphery: consequences for color coding of vehicle signals. Transportation Human Factors, 2(2), 135-150.

Sivak, M., Flannagan, M. J., Sato, T., Traube, E. C., \& Aoki, M. (1994). Reaction times to neon, LED, and fast incandescent brake lamps. Ergonomics, 37(6), 989-994.

Taylor, G. W., \& Ng, W. K. (1981). Measurement of effectiveness of rear-turn-signal systems in reducing vehicle accidents from an analysis of actual accident data (SAE Technical Paper No. 810192). Warrendale, PA: Society of Automotive Engineers. 
DOT HS 811037

September 2008

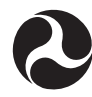

U.S. Department

of Transportation

National Highway

Traffic Safety

Administration

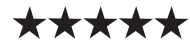

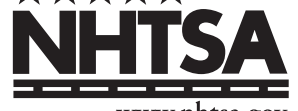

www.nhtsa.gov 